\title{
Atmospheric Mining in the Outer Solar System: Outer Planet Resource Processing, Moon Base Propulsion, and Vehicle Design Issues
}

\author{
Bryan Palaszewski \\ NASA John H. Glenn Research Center \\ Lewis Field \\ MS 5-10 \\ Cleveland, $\mathrm{OH} 44135$ \\ (216) 977-7493 Voice \\ (216) 433-5802 FAX \\ bryan.a.palaszewski@nasa.gov \\ Fuels and Space Propellants Web Site: \\ http://www.grc.nasa.gov/WWW/Fuels-And-Space-Propellants/foctopsb.htm
}

\begin{abstract}
Atmospheric mining in the outer solar system has been investigated as a means of fuel production for high energy propulsion and power. Fusion fuels such as Helium 3 (3He) and deuterium can be wrested from the atmospheres of Uranus and Neptune and either returned to Earth or used in-situ for energy production. Helium 3 and deuterium were the primary gases of interest with hydrogen being the primary propellant for nuclear thermal solid core and gas core rocket-based atmospheric flight. A series of analyses were undertaken to investigate resource capturing aspects of atmospheric mining in the outer solar system. This included the gas capturing rate, storage options, and different methods of direct use of the captured gases. While capturing 3He, large amounts of hydrogen and $4 \mathrm{He}$ are produced. Analyses of orbital transfer vehicles (OTVs), landers, and in-situ resource utilization (ISRU) mining factories are included. Preliminary observations are presented on near-optimal selections of moon base orbital locations, OTV power levels, and OTV and lander rendezvous points. Based on earlier propulsion investigations, the analyses of round trip OTV flights from Uranus and Neptune to their major moons with a 10-Megawatt electric (MWe) OTV power level and a 200 metric ton (MT) lander payload were selected. The OTV power level was based on delivering a relatively short OTV trip time and minimization of the number of lander flights. Moon base sites at Uranus and Neptune and the OTV requirements to support them will also be addressed. These analyses will include all of the major moons of Uranus and Neptune. In addition, the total masses and mass delivery schedules needed for atmospheric mining are presented. Additional analyses are presented for science and resource prospecting OTV and lander missions.
\end{abstract}

\section{Nomenclature}

$\begin{array}{ll}3 \mathrm{He} & \text { Helium } 3 \\ 4 \mathrm{He} & \text { Helium (or Helium } 4) \\ \text { AMOSS } & \text { Atmospheric mining in the outer solar system } \\ \text { ASC } & \text { Aerospacecraft for atmospheric mining } \\ \text { CC } & \text { Closed cycle } \\ \text { D } & \text { Deuterium } \\ \text { delta-V } & \text { Change in velocity }(\mathrm{km} / \mathrm{s}) \\ \text { GCR } & \text { Gas core rocket } \\ \text { H2 } & \text { Hydrogen } \\ \text { He } & \text { Helium } 4\end{array}$

* Leader of Advanced Fuels, AIAA Associate Fellow 


$\begin{array}{ll}\text { ISRU } & \text { In Situ Resource Utilization } \\ \text { Isp } & \text { Specific Impulse (s) } \\ \text { ITV } & \text { Interplanetary transfer vehicle } \\ \text { K } & \text { Kelvin } \\ \text { kWe } & \text { Kilowatts of electric power } \\ \text { LEO } & \text { Low Earth Orbit } \\ \text { MT } & \text { Metric tons } \\ \text { MWe } & \text { Megawatts of electric power (power level) } \\ \text { NEP } & \text { Nuclear Electric Propulsion } \\ \text { NPP } & \text { Nuclear Pulse Propulsion } \\ \text { NTP } & \text { Nuclear Thermal Propulsion } \\ \text { NTR } & \text { Nuclear Thermal Rocket } \\ \text { OC } & \text { Open cycle } \\ \text { OTV } & \text { Orbital Transfer Vehicle } \\ \text { O2 } & \text { Oxygen } \\ \text { PPack } & \text { Physics Package for nuclear pulse propulsion } \\ \text { PPB } & \text { Parts per billion }\end{array}$

\section{Atmospheric mining in the outer solar system}

Atmospheric mining of the outer solar system is one of the options for creating nuclear fuels, such as $3 \mathrm{He}$, for future fusion powered exploration vehicles or powering reactors for Earth's planetary energy. Uranus' and Neptune's atmospheres would be the primary mining sites, and robotic vehicles would wrest these gases from the hydrogen-helium gases of those planets. While preliminary estimates of the masses of the mining vehicles have been created (Refs. 1-5), additional supporting vehicles may enhance the mining scenarios. Storing the mined gases at automated bases on outer planet moons was conceived to ease the storage requirements on interplanetary transfer vehicles (that would return the cryogenic gases to Earth).

\section{Resource capturing studies}

Studies of the gas capture rate and its influence on mining time in the atmosphere were conducted. Aerospacecraft cruisers have been identified as a "best" solution for atmospheric mining (Ref. 1-12). To power these vehicles, atmospheric hydrogen gas would be liquefied and used as rocket propellant for the ascent to orbit. A gas core rocket is a likely candidate. Gaseous or liquid hydrogen would be used to power the engines during atmospheric mining operations. Helium 3 (3He) would be separated from the atmospheric hydrogen and helium (4He) captured, liquefied and stored as a payload that would be returned to orbit. A $500-\mathrm{kg}$ payload of $3 \mathrm{He}$ is captured during the mining time. Table I provides the amount of $3 \mathrm{He}$ in the outer planet atmospheres.

Table I. Fraction of helium 3 in outer planet atmospheres

\begin{tabular}{|l|r|r|r|}
\hline & Uranus & Neptune \\
\hline Amount of 3He in 4He & $1.00 \mathrm{E}-04$ & $1.00 \mathrm{E}-04$ \\
\hline Amount of 4He in atmosphere & 0.152 & 0.19 \\
\hline Amount of 3He in atmosphere & $1.52 \mathrm{E}-05$ & $1.90 \mathrm{E}-05$ \\
\hline
\end{tabular}




\section{Vehicle, Mission, and Propulsion Studies}

\section{A. Moon Base Transportation and Mission Planning}

In order to illustrate the use and storage of helium 3 and deuterium, a series of analyses were conducted regarding transportation options. Several steps are needed to store the nuclear fuels. An aerospacecraft (ASC) must mine the gases from the planet's atmosphere. The ASC propulsion is typically an open cycle (OC) nuclear gas core rocket (GCR). After mining, the ASC ascends to low orbit, and then rendezvous with an orbiting tanker or orbital transfer vehicle. The OTV and ASC rendezvous at an altitude compatible with both vehicles. After the rendezvous, the OTV accepts the mined cryogenic gases from the ASC, and, the OTV begins a low thrust spiral trajectory to the storage point. In these analyses, an outer planet moon was selected as the storage point. However, as an alternative storage point, an in-space base with artificial gravity was also included in these analyses; the in-space base would be in orbit about the target moon. At the moon, the OTV and lander will rendezvous in high orbit about the outer planet moon. The OTV will deliver the mined fluids to a lander. The lander will refuel the OTV from hydrogen mined on the moon; as the target moon has a very low gravity, the propellant factory there may use some amount of artificial gravity on the moon's surface as well. The OTV will return to the rendezvous altitude to await the next ASC delivery. The lander will return to the moon with the mined fluids. On the moon, the lander propulsion system will be refueled with oxygen and hydrogen from the water ice from the moon. Hydrogen for the OTV refueling will also be loaded aboard the lander. The ASC-OTV-Lander ISRU cycle (with artificial gravity augmentation from an in-space base) continues until the needed helium 3 and deuterium are stored on the moon or at the in-space base. References 13 to 33 provide many options for nuclear power and nuclear propulsion to support this mining. The individual ASC masses are approximately 1,000 MT (Ref. 1).

\section{B. Mission analyses for moon basing}

In the planned mining operations, there are several transportation elements. The ASC captures the atmosphere in-situ and extracts the helium 3. The ASC then ascends to an $800 \mathrm{~km}$ orbit to rendezvous with an orbital transfer vehicle (OTV). The OTV uses low thrust nuclear electric propulsion (NEP). An $800 \mathrm{~km}$ orbit was selected as it is a high enough altitude to prevent the atmospheric drag from affecting the NEP OTV (Refs. 1-12).

The OTV then transports the helium 3 payload(s) to an orbit about a small moon of the planet. The moon is selected to have a low gravity level, so that entering and exiting the moons orbit requires a low delta- $\mathrm{V}$. The moon should be an ice and rock body that can be mined for water. Water is mined on the moon to create oxygen and hydrogen to fuel high thrust chemical propulsion systems. A chemical propulsion lander then ascends from the moon to transfer the helium 3 to the moon's surface. The lander also delivers liquid hydrogen to refuel the OTV. After picking up the helium 3 payload, the lander returns to the moon's surface. After soft landing the payload on the moon, a storage facility will hold the helium 3 until needed. Possible storage times can be many years or decades, as the applications of the helium 3 are nuclear fusion fuels for interplanetary and interstellar missions, etc. The time to mine the needed fuels can literally be decades.

\section{Where do you store fuels?}

Storing fuels in low orbit above the planet is generally not desirable. The storage facility may be subject to large variations in the planet's atmosphere, and may also unintentionally reenter the planet's atmosphere. The 800 $\mathrm{km}$ altitude is above the altitude where the nominal atmospheric drag would seriously affect the NEP OTV's orbit. The ASC total delta-V capability is $20.1 \mathrm{~km} / \mathrm{s}$. The ASC delta-V includes the launch from the mining altitude at subsonic speed to a low altitude orbital velocity and then the additional ascent to the $800 \mathrm{~km}$ orbital altitude. Storing the fuels in a place with some sensible gravity is an attractive option. Many processes for mining, 
extracting, purifying, and larger scale production would benefit from a moon with gravity. Therefore an outer planet moon was sought as a base for facility operations and fuel storage.

\section{Moon selection}

The moon selection for the storage of the cryogenic mined fluids was based on several factors. The moon should be a water ice and rock body. The water ice will be needed to produce the propellants for the low-thrust OTV and the lander. The moon should be in an orbit away from the potential debris of the planet's ring plane. Being away from the rings minimizes the hazards that the OTV will have to traverse and avoid. The moon should have a high enough gravity level to ease or simplify the propellant production operations. The moon's gravity should be low enough to allow easy transportation onto and off of the surface with a relatively small delta-V. It is also an attractive option to select a moon far from rings, and away from the planet's radiation environment. Also, one should select small moon with minimal gravity, but enough gravity for mining operations. A cryogenic environment is excellent for long term helium 3 storage (below a temperature of $4 \mathrm{~K}$ ).

At Uranus, the five major moons were selected for these AMOSS OTV and lander operations and analyses. The five moons have a range of delta- $\mathrm{V}$ values for round trips from those moons' surfaces. Tables II and III provide the delta- $\mathrm{V}$ needed for these round trips for the moons of Uranus and Neptune, respectively. The delta- $\mathrm{V}$ values were computed with standard orbital mechanics equations. At Miranda, the round trip escape delta- $\mathrm{V}$ was $0.5 \mathrm{~km} / \mathrm{s}$ for the lander mission; it is moon with the smallest delta- $\mathrm{V}$. The delta- $\mathrm{V}$ values for each moon included the escape velocity from the moon, for each leg of the round trip, and a $20 \%$ additional delta-V for gravity losses. Titania required the largest round trip delta- $\mathrm{V}$; that moon has a spectral signature that strongly implies that it is an ice and rock body (Ref. 28 and 29). The moon's escape velocity is approximately $0.95 \mathrm{~km} / \mathrm{s}$ (including gravity losses, uncertainties, etc.). The round trip delta- $\mathrm{V}$ was therefore $1.9 \mathrm{~km} / \mathrm{s}$.

Tables IV and V list the round trip delta-V values for travel from Uranus to its moons and from Neptune to its moons, respectively. The delta-V values were computed with standard orbital mechanics equations. For Titania, the low-thrust round trip orbital delta- $\mathrm{V}$ would be $22.4 \mathrm{~km} / \mathrm{s}$, which includes the required plane change of 0.14 degrees. The Titania lander that would rendezvous with an OTV would deliver $1.9 \mathrm{~km} / \mathrm{s}$ (for the round trip lander flight). Thus, the rendezvous could occur near the escape conditions for the moon or at the lower orbital altitude. The OTV is sized to deliver $22.4 \mathrm{~km} / \mathrm{s}$ (equal to a round trip flight to Titania from low Uranus orbit). For Neptune, the eight major moons were investigated. Thalassa required a round trip OTV delta-V of $9.4 \mathrm{~km} / \mathrm{s}$. The round trip lander delta-V was $80 \mathrm{~m} / \mathrm{s}$. For Triton, the round trip OTV mission required a delta-V of $26.2 \mathrm{~km} / \mathrm{s}$, and the round trip lander delta- $\mathrm{V}$ was $3.5 \mathrm{~km} / \mathrm{s}$.

Table II. Uranus Moon Lander delta-V Values

\begin{tabular}{|l|r|r|r|}
\hline Moon & $\begin{array}{l}\text { Round-trip } \\
\text { delta-V }(\mathrm{km} / \mathrm{s})\end{array}$ & $\begin{array}{l}\text { delta-V } \\
\text { Capability }(\mathrm{km} / \mathrm{s})\end{array}$ & Sizing Category \\
\hline Miranda (UV) & 0.44 & 0.5 & a \\
\hline Ariel (UI) & 1.34 & 1.4 & $\mathrm{~b}$ \\
\hline Umbriel (UII) & 1.24 & 1.3 & $\mathrm{~b}$ \\
\hline Titania (UII) & 1.85 & 1.9 & $\mathrm{c}$ \\
\hline Oberon (UIV) & 1.74 & 1.8 & $\mathrm{c}$ \\
\hline
\end{tabular}


Table III. Neptune Moon Lander delta-V Values

\begin{tabular}{|l|r|r|r|}
\hline Moon & $\begin{array}{l}\text { Round-trip } \\
\text { delta-V }(\mathrm{km} / \mathrm{s})\end{array}$ & $\begin{array}{l}\text { delta-V } \\
\text { Capability }(\mathrm{km} / \mathrm{s})\end{array}$ & Sizing Category \\
\hline Naiad (NIII) & 0.06 & $\mathbf{0 . 0 6}$ & a \\
\hline Thalassa (NIV) & 0.08 & 0.08 & a \\
\hline Despina (NV) & 0.13 & 0.14 & b \\
\hline Galatea (NVI) & 0.17 & 0.18 & b \\
\hline Larissa (NVII) & 0.19 & 0.19 & b \\
\hline S/2004 N1 & & & \\
\hline Proteus (NVIII) & 0.44 & 0.50 & c \\
\hline Triton & 3.49 & 3.50 & d \\
Nereid & 0.37 & 0.40 & c \\
\hline
\end{tabular}

Table IV. Uranus to Moon Orbital Transfer delta-V Values

Planet to moon orbital transfer, low thrust delta-V delta-V (km/s), 1 way delta-V ( km/s), 2 way delta-V capability $(\mathrm{km} / \mathrm{s})$

\begin{tabular}{|l|c|c|c|}
\hline Miranda (UV) & 8.216 & 16.432 & 16.5 \\
\hline Ariel (UI) & 9.320 & 18.640 & 18.7 \\
\hline Umbriel (UII) & 10.162 & 20.324 & 20.4 \\
\hline Titania (UIII) & 11.180 & 22.360 & 22.4 \\
\hline Oberon (UIV) & 11.675 & 23.350 & 23.4 \\
\hline
\end{tabular}

Table V. Neptune to Moon Orbital Transfer delta-V Values

Planet to moon orbital transfer, low thrust delta-V $\operatorname{delta-V}(\mathrm{km} / \mathrm{s}), 1$ way delta-V $(\mathrm{km} / \mathrm{s}), 2$ way delta-V capability $(\mathrm{km} / \mathrm{s})$

\begin{tabular}{|l|c|c|c|}
\hline Naiad (NIII) & 4.808 & 9.616 & 9.7 \\
\hline Thalassa (NIV) & 4.675 & 9.350 & 9.4 \\
\hline Despina (NV) & 4.950 & 9.900 & 9.9 \\
\hline Galatea (NVI) & 5.860 & 11.720 & 11.8 \\
\hline Larissa (NVII) & 6.720 & 13.440 & 13.5 \\
\hline S/2004 N1 & too small & & 17.5 \\
\hline Proteus (NVIII) & 8.736 & 17.472 & 26.2 \\
\hline Triton & 13.072 & 26.144 & 30.6 \\
\hline Nereid & 15.269 & 30.538 & \\
\hline
\end{tabular}




\section{E. OTV Propulsion assumptions and sizing}

An OTV propulsion and power model was developed using historical data (Refs. 9 and 30 to 32). The Isp and efficiency of the electric propulsion systems were 5,000 seconds with thruster efficiencies of 50\% for each design. These design points are typical of advanced designs of either magneto-plasma-dynamic (MPD) or pulse inductive thrusters (PIT). While hydrogen is suggested for both thrusters, the possibilities of the higher Isp option using inert gases (xenon, krypton, etc.) is also viable. While hydrogen is more plentiful on the icy moons, inert gases have been detected on the Earth's Moon; it is suggested that these gases may also be available at the outer planet moons.

As the delta- $\mathrm{V}$ is so large for the transportation system, chemical propulsion is impractical. The OTV sizing was conducted for a wide range of power levels: $0.5 \mathrm{MWe}$ to $30 \mathrm{MWe}$. Three nuclear reactor specific masses were used: 10, 20, and $40 \mathrm{~kg} / \mathrm{kWe}$. The thruster technology delivers an Isp of either 5,000 at an engine efficiency of 50 percent. These technology levels represent MPD thruster capabilities with hydrogen as the propellant. The OTV propulsion dry mass (fixed mass), apart from and in addition to the reactor mass, was $101 \mathrm{MT}$ and the propellant tankage mass was $5 \%$ of the mass of the required propellant.

The dry mass scaling equation used was (Refs. 1 and 2):

Mdry,stage $(\mathrm{kg})=$ reactor specific mass $(\mathrm{kg} / \mathrm{kW}) \cdot \mathrm{P}(\mathrm{kWe})+0.05 \cdot \mathrm{Mp}(\mathrm{kg})+$ fixed mass $(\mathrm{kg})$

The low thrust OTV delta-V values are presented in Table IV (for Uranus) and Table V (for Neptune) for the round trip missions. This delta- $\mathrm{V}$ value can accommodate round trip flights from a moon to Uranus or from a moon to Neptune, respectively.

\section{F. OTV results:}

The initial masses of the OTVs were estimated and the results are provided in Ref. 1. The 5,000 second Isp cases were would likely be selected if the goal were the fastest trip time (Ref. 1). For the Miranda mission, with the 10 MWe power level, a 101 MT dry mass, and the lightest OTV reactor $(10 \mathrm{~kg} / \mathrm{kWe})$, the trip time is 229 days. The longest trip time (with the heaviest reactor, $40 \mathrm{~kg} / \mathrm{kWe}$ ) for the $101 \mathrm{MT}$ dry mass and $10 \mathrm{MWe}$ case is 569 days. At Titania, with the 101 MT dry mass, at a 10 MWe power level with the lightest reactor, the shortest trip time is 334 days and with the heaviest reactor, the longest time is 832 days. At Thalassa, with the 101 MT dry mass, at 10 MWe, the shortest trip time is 127 days (lightest reactor, $10 \mathrm{~kg} / \mathrm{kWe}$ ) and the longest trip time is 298 days (with the heaviest, $40 \mathrm{~kg} / \mathrm{kWe}$ reactor).

The power level of 10 MWe appears to be the most acceptable, with a 20 and 30 MWe power level being too high, with no significant trip time benefits over $10 \mathrm{MWe}$. The $0.5 \mathrm{MWe}$ cases have very long trip times, and were not attractive for most cases. Additional detailed results regarding OTV initial mass, propellant mass, and the (round trip) trip time required for OTV refueling are presented in Ref. 1.

\section{G. Lander propulsion assumptions and sizing}

The lander's mission is to deliver hydrogen to the OTV and return to the moon with the helium 3 or deuterium payload(s). The round trip delta- $\mathrm{V}$ values are provided in Tables II and III, for Uranus and Neptune, respectively This $1.9 \mathrm{~km} / \mathrm{s}$ delta- $\mathrm{V}$ value represents the energy to reach escape conditions from the moon Titania 
and return to the moon. Thus, the lander has the capability to reach escape conditions to rendezvous with the OTV. The lander was designed with an oxygen hydrogen main propulsion system. The lander Isp was varied from 400 to 480 seconds. The dry mass scaling equation was (Refs. 1 and 2):

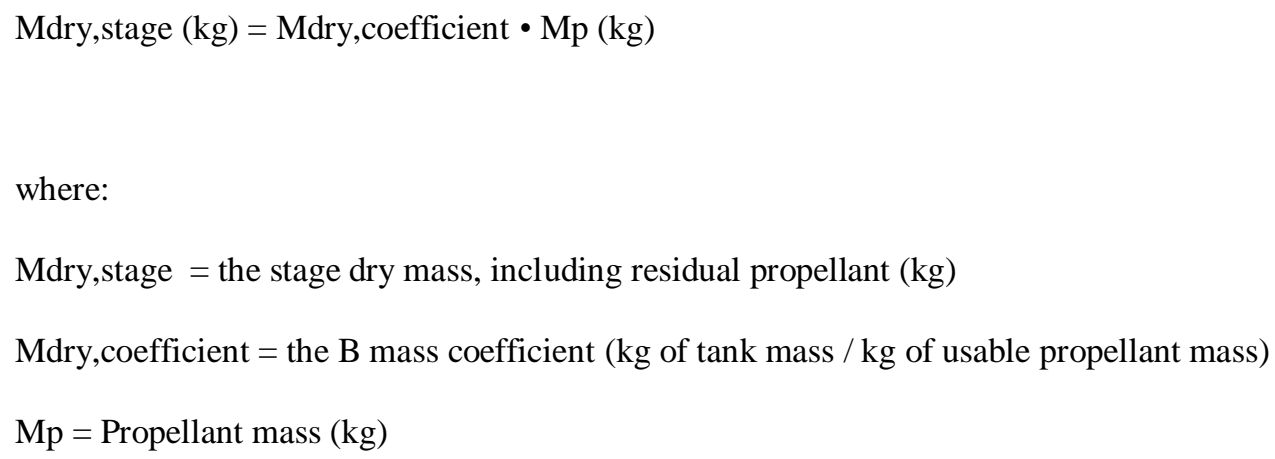

The value of the B parameter would be typical of landers with smaller propellant loads. The payload masses for the analyses were 50,100, and 200 MT. The tankage to contain the payload of fuel is 10 percent of that payload mass. The landers are sized to carry the full payload of fuel on a round trip flight. This is the worst case for abort scenarios, where the lander may miss an OTV refueling rendezvous and have to return its full payload to the moon.

\section{H. Lander results}

The lander initial mass, propellant mass, and number of flights to resupply the OTV missions are presented in Ref. 1. In some cases, the lander propellant masses are actually quite modest. The following results are for the Miranda lander, with a B coefficient of 0.4. For the 50 MT payloads with a 400-s Isp, the propellant masses are 7.9 MT and with 200 MT of payload, the propellant mass is 32 MT. With a 480-s Isp, the propellant masses are 6.5 MT and 26 MT, respectively.

For Titania, with a B coefficient of 0.4, and a 50 MT payload and an Isp of $400 \mathrm{~s}$, the propellant mass is 45.6 MT; for the 200 MT payload, the propellant mass is 182.5 MT. With a B coefficient of 0.4 , and a 50 MT payload and an Isp of $480 \mathrm{~s}$, the propellant mass is $34.1 \mathrm{MT}$; for the same coefficient and Isp, with the $200 \mathrm{MT}$ payload, the propellant mass is 136.5 MT. Many additional results regarding lander mass, propellant mass, and number of flights required for OTV refueling are presented in Ref. 1.

Certainly, the 200 MT payload lander flights require the fewest flights. Transferring all of the OTV propellant in one refueling will seemingly be more effective than awaiting 2 or 4 times the number of lander refueling flights. Power aboard the OTV can help maintain the cryogenic liquids at their appropriate temperatures and pressures during the propellant transfers. 


\section{In-space (space base) factory masses}

Due to the extremely low gravity on the outer planet moons, in-space processing with artificial gravity was assessed. Several historical space base designed were reviewed and their configurations were modified to accommodate large scale propellant processing (Refs. 37 and 38). The space bases would be placed in orbit about the outer planet moon. Deliveries of raw materials would be made from the outer planet moon's surface.

The space base masses that contain the factories can be in several different configurations. The range of masses, from the minimal robotic option to the highest masses for human tended bases, are shown in Ref. 1. Figure 1 provides the in-space factories or space base design masses. For the outer planets, the smaller robotic options may be the most attractive. With smaller robotic bases, the overall transportation costs will be reduced. The power levels of the robotic space bases were between 1 and $5 \mathrm{MWe}$. The mass of $50 \mathrm{MT}$ was allocated to the power system, and the resultant power level is based on the technology levels of 10,20 , and $40 \mathrm{~kg} / \mathrm{kWe}$. If the technology level is $40 \mathrm{kw} / \mathrm{kWe}$, the total power level available is $1.25 \mathrm{MWe}$. If the available technology level is $10 \mathrm{~kg} / \mathrm{kWe}$, the power level would be 5 MWe.

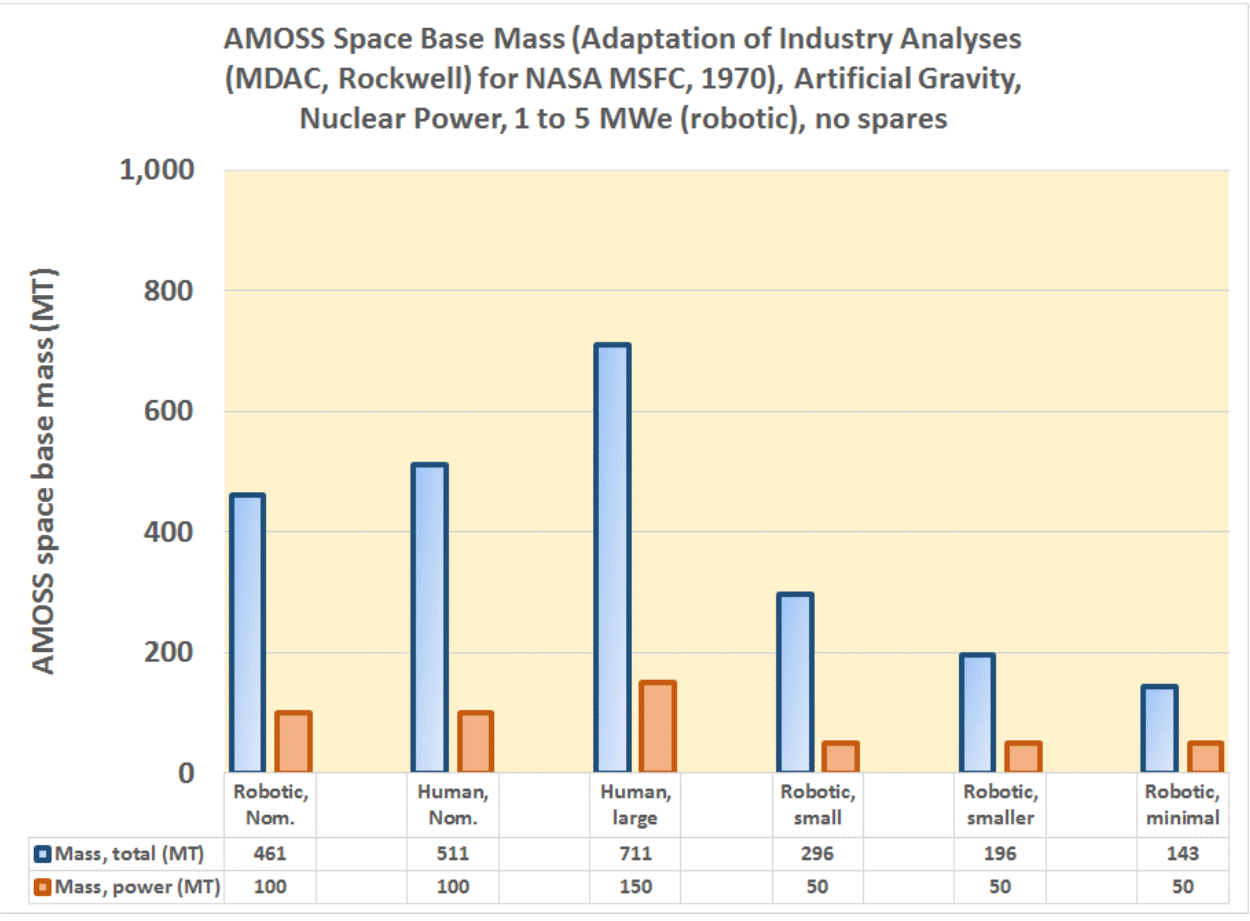

Figure 1. Space base mass estimates (Ref. 1)

\section{Preliminary Optimization(s) and Observations}

Establishing an optimum transportation system will be influenced by many factors: the OTV mass and power level, the payload mass of the lander and the selection of the moon for the mining factories. Several optima will be created based on the size and mass of the moon selected. The moon's mass will strongly influence the propellant mass needed for the refueling of its oxygen/hydrogen propulsion system and the time needed for creating the fuel for the OTV. 


\section{A, Mining transportation masses and architectures}

Two examples of the estimated transportation system masses are presented in Figure 2 for Uranus and Figure 3 for Neptune. The OTV and lander masses for all of the major moons of each planet were assessed. As noted, these moons represent the moons with the smallest and largest delta- $\mathrm{V}$ values required for moon landing operations at each planet. Figures 2 and 3 represents the cases with the NEP OTV operating with an Isp of 5,000 s and a reactor alpha of $10 \mathrm{~kg} / \mathrm{kW}$. For all cases, a lander Isp value of $460 \mathrm{~s}$ was selected for the comparison. Many other such comparisons can be created from the large set of data presented in Ref. 1.

With the OTVs, the 10 MWe power level appears to be the most acceptable. The initial mass of the OTV with power levels of 20 and $30 \mathrm{MWe}$ is too high in comparison with the $10 \mathrm{MW}$ cases, with no significant trip time benefits over the OTV at the 10 MWe power level. For the $101 \mathrm{MT}$ dry mass case for Miranda, at $10 \mathrm{~kg} / \mathrm{kWe}$, and at 5,000 seconds of Isp value, the trip time for the $30 \mathrm{MW}$ level is 152 days versus 228 days at the $10 \mathrm{MW}$ level. With the $40 \mathrm{~kg} / \mathrm{kWe}$ case (with the same Isp and dry mass), the trip time at $30 \mathrm{MWe}$ is 493 days versus 569 days for the $10 \mathrm{MWe}$ case. The OTV trip times are a significant issue. Many flight times are 100's of days. Initially, a single 1 MT payload of helium 3 or deuterium would fly on each OTV flight. Multiple helium 3 or deuterium payloads will have to be manifested on the OTVs.

While the OTV and the lander can rendezvous at the moon's escape conditions, it may be more stable to conduct the propellant and payload transfers at a high moon orbit, but not at or beyond the moon's escape conditions. The OTV trip time to enter and establish a suitably stable orbit for the propellant transfer from the lander will increase, but that increase is likely a small number of days.

For the OTVs, the 7 year period for replacement was selected based on the lifetime of reactors noted for the SP-100 space nuclear reactor systems (Ref. 39). In Ref. 1, the total number of OTV flights that are possible for a 7 and 10 year OTV operating life are depicted. It is clear that the smaller moons near the planet, requiring shorter flight times will be able to accomplish more round trip flights in the 7 to 10 year reactor lifetimes. In the Ref. 1 data, the Miranda OTV is able to conduct 11 round trip in the 7 year lifetime. For Titania, only 7 round trips are possible in the 7 year reactor lifetime. Similarly, in the Ref. 1 data, the Thalassa OTV can complete 20 round trips while the Triton OTV can only complete 6 round trip flights in the 7-year reactor lifetime.

Lander payloads of 200 MT provide the minimal number of lander flights. Small lander payloads may be acceptable, but the processing on the moon of the propellant, the propellant loading, and the cryogenic hydrogen loading may favor the largest payload capacity lander. With the 200 MT hydrogen payload, the number of lander flights needed to refuel the 101 MT dry mass (5,000 seconds Isp) OTV for Miranda is 1 flights for the $10 \mathrm{~kg} / \mathrm{kWe}$ case and 2 flights for the $40 \mathrm{~kg} / \mathrm{kWe}$ case (Ref. 1). For the $50 \mathrm{MT}$ lander flights, the numbers of flights were 2 for the $10 \mathrm{~kg} / \mathrm{kW}$ case and 5 for the $40 \mathrm{~kg} / \mathrm{kW}$ case (Ref. 1). Landers might be further optimized by increasing their payload capacity, which would further reduce the number of flights.

Fuel processing, and robotic storage and transportation of helium 3 and deuterium will likely be a major challenge. Physics Package (PPack) factory will have large uncertainties in its mass estimate. If the mass from Earth becomes too high (making the ISRU case potentially untenable or unsustainable), it is likely that the factory itself can be created from in-situ resources. Ice and rock from moon mining and water extraction and purification will be required. Selecting a small moon with minimal gravity may be another challenge, and experiments will be needed to prove which gravity level is sufficient for mining operations (i.e., is $0.01 \mathrm{G}$ too low a gravity level for this processing?). 


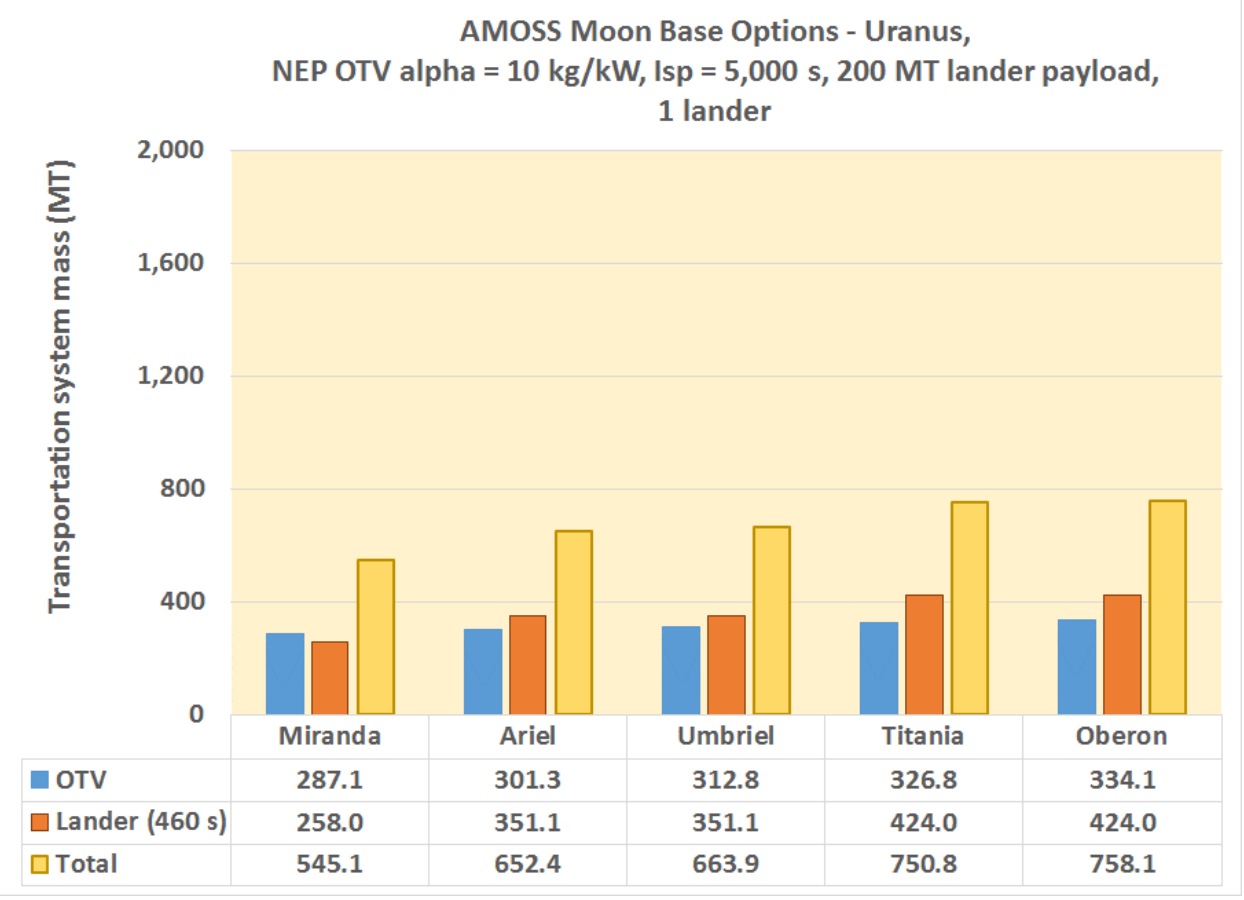

Figure 2. Uranus - Transportation System Mass - NEP alpha $=10 \mathrm{~kg} / \mathrm{kW}$, Isp $=5,000 \mathrm{~s}$, Lander Isp $=460 \mathrm{~s}$ (one lander included in each case).

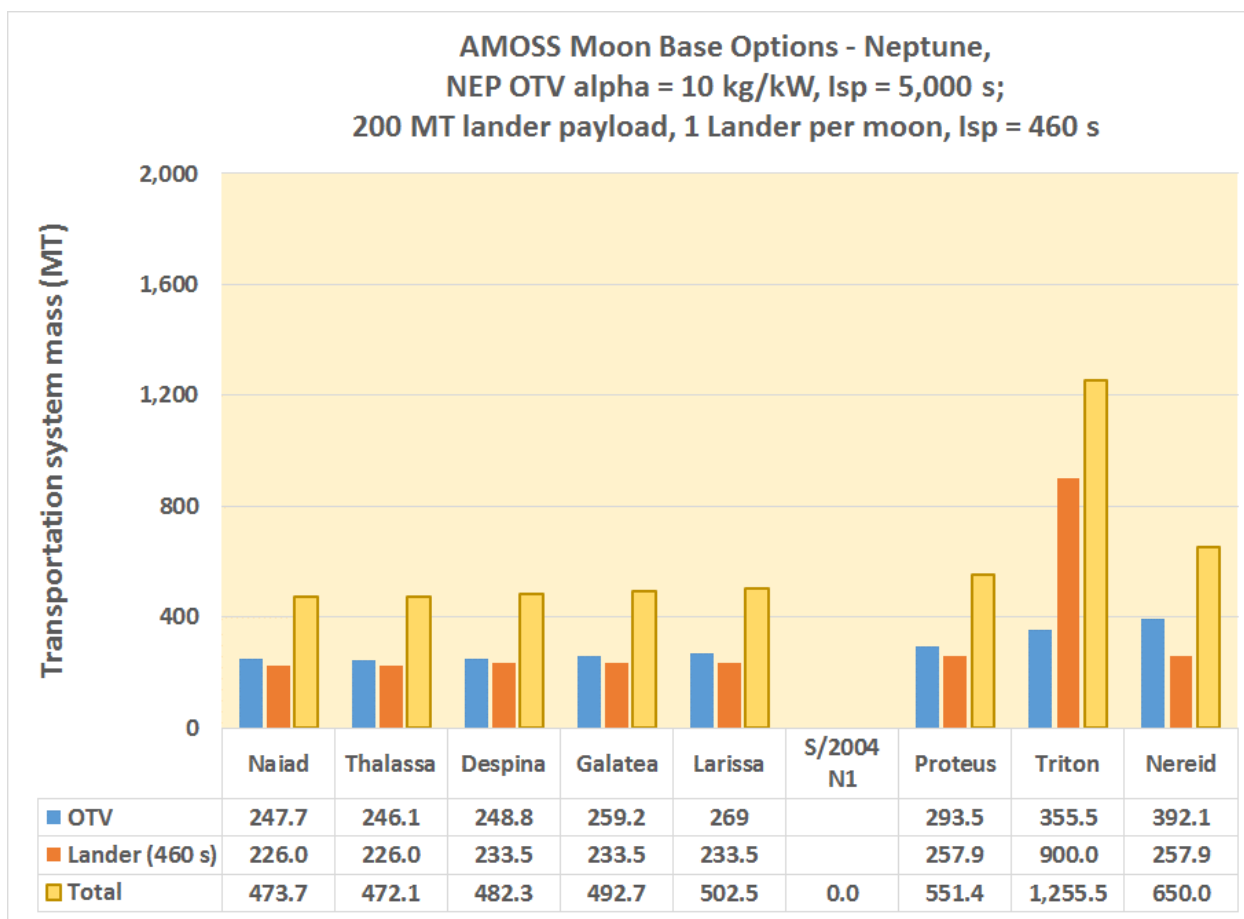

Figure 3. Neptune - Transportation System Mass - NEP alpha $=10 \mathrm{~kg} / \mathrm{kW}$, Isp $=5,000 \mathrm{~s}$, Lander Isp $=460 \mathrm{~s}$ 
To see the influence of replacement scheduling and vehicle lifetime, an overall architecture assessment was conducted. Based on the vehicle mass data from Refs. 1 to 12, a set of nominal masses were selected that are representative of the major architecture components. Those components are shown in Figure 4. The initial masses are for the ASCs, the landers, the OTVs and the in-space factories Ref. 1).

With the mass estimates of the ASCs, landers, OTVs and space base factories, the overall AMOSS operational mining architecture masses can be estimated. Figure 4 provides the nominal major elements and masses for the AMOSS operational mining architecture. While each individual architecture has more specific masses for the OTVs and landers, these nominal values will provide a guide for comparative estimates.

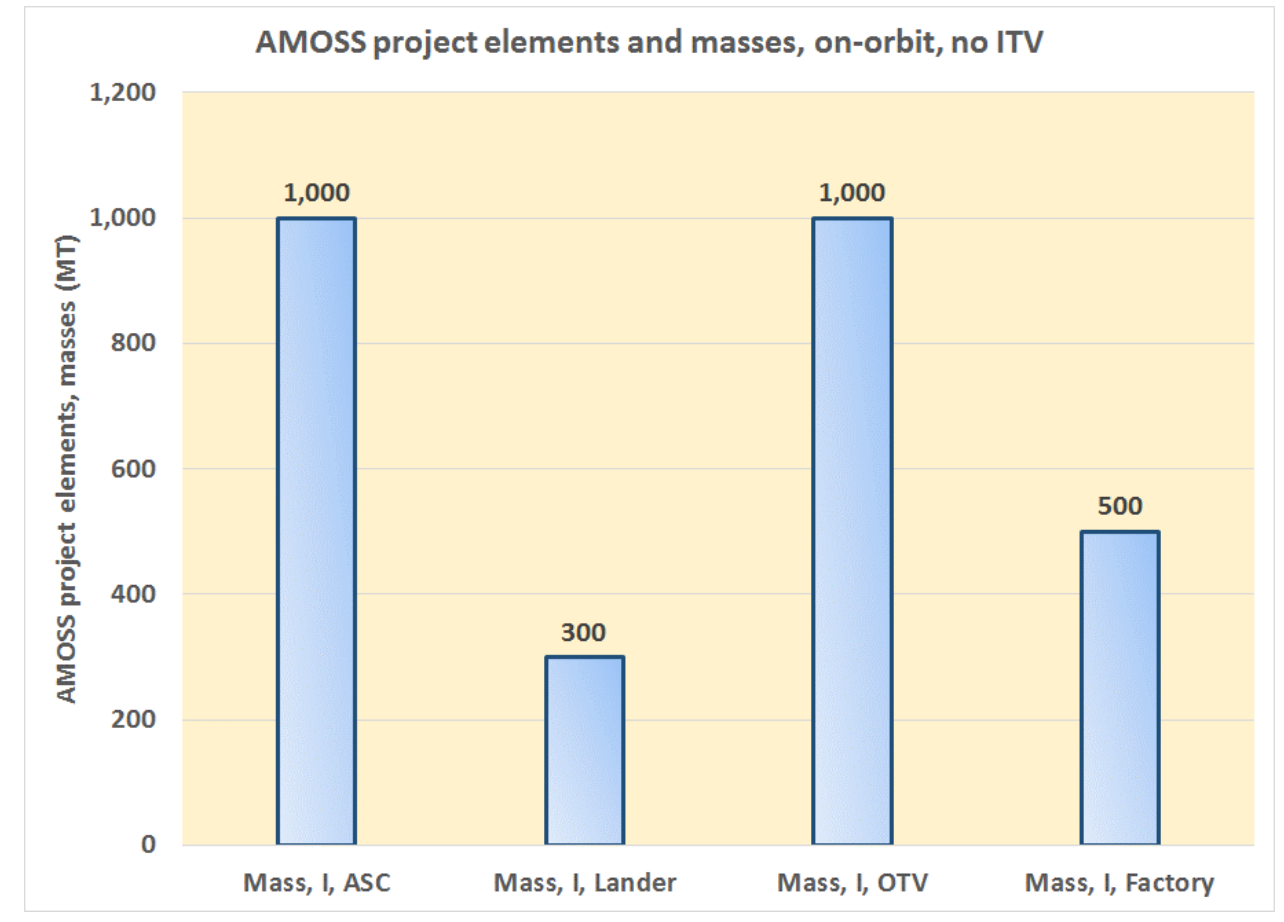

Figure 4. AMOSS on-orbit mass requirements for individual elements, nominal case. (Ref. 1)

The total AMOSS operational mining masses were estimated for 10, 20 and 30 years. The mining delivery schedules were developed for Uranus and Neptune. Two major moon cases are presented; both Miranda at Uranus and Thalassa at Neptune were assessed. These moons required the smallest overall transportation mass for AMOSS mining.

In Figure 5, the total mass of the Miranda architecture over a 10 year period is shown. There are two major summations: I for initial deployment and $\mathrm{R}$ for replacement components. This mass summation is representative of the masses needed if the elements must be replaced and the replacement mass is assumed to be 10 percent of the initial masses. The masses shown in the figures do not include the interplanetary transfer vehicles (ITVs) needed for the flight to Uranus. Approximately 11,040 MT (replacement masses) and 110,400 MT (initial masses) of vehicles would be needed over the 10 year period. 
The masses of the individual mining architecture elements are presented in Figure 6. The overall lifetime assumptions for the architecture elements are provided in Table VI. In the mining architecture estimates, the number of ASCs was 100. The 100 ASC number was selected based on a lifetime of 100 missions for the ASC. In this Miranda example, the mining architecture is delivering 5,000 MT of 3He and D to ultimately refuel a nuclear vehicle. The 5,000 MT value represented a nuclear pulse propulsion vehicle for trips from Earth to the outer planets (Ref. 40). The ASC has a payload delivery capacity of 0.5 MT. Thus, 10,000 ASC flights are needed to deliver the 5,000 MT of $3 \mathrm{H}$ and D propellants.

The OTV lifetime was 7 years (Refs. 1 and 39). The round trip flight time for Miranda mining was 229 days. In a 7 year reactor lifetime, 11 round trip flights were possible. For Thalassa, the round trip flight time was 127 days. In a 7 year reactor lifetime, 20 round trip flights were possible.

To deliver the 5,000 MT of nuclear fuels, a number of OTV flights are needed to transport the fuel from ASCs low orbit to the moon.an its space based factory. The OTV was designed with a 75 MT OTV payload capacity; therefore the number of OTVs is 67 . In this example. A total of 77 flights was included. The 77 OTV number will deliver a final payload of 5,775 MT of fuel. This payload number is representative of the amount of delivered fuel with a certain amount of loss in processing and transportation.

The landers were sized for a 200 MT round trip payload. The lander lifetimes were 10 round trip flights. In this example, to support the 77 OTV flights, 8 landers are required. The factory lifetime was 5 years.

Appendix A provides the Miranda architecture cases for 10, 20 and 30 year mining schedules; there are 100 ASCs in these analyses. Appendix B shows the results for Miranda with 10 ASCs per architecture. Appendix C presented the Thalassa architecture for 10, 20 and 30 year mining schedules. The results of the three sets of analyses are presented in Figure 7. It is clear that reducing the number of ASCs from 100 to 10 is a major factor in the architecture mass reduction. However, it is unlikely that only 10 ASCs would be able to accomplish the mining tasks; using 10 ASCs implies that each ASC would fly 1,000 flights. With 100 ASCs, each vehicle would fly only 100 missions.

Table VI. AMOSS vehicle lifetimes and replacement schedules: Miranda at Uranus

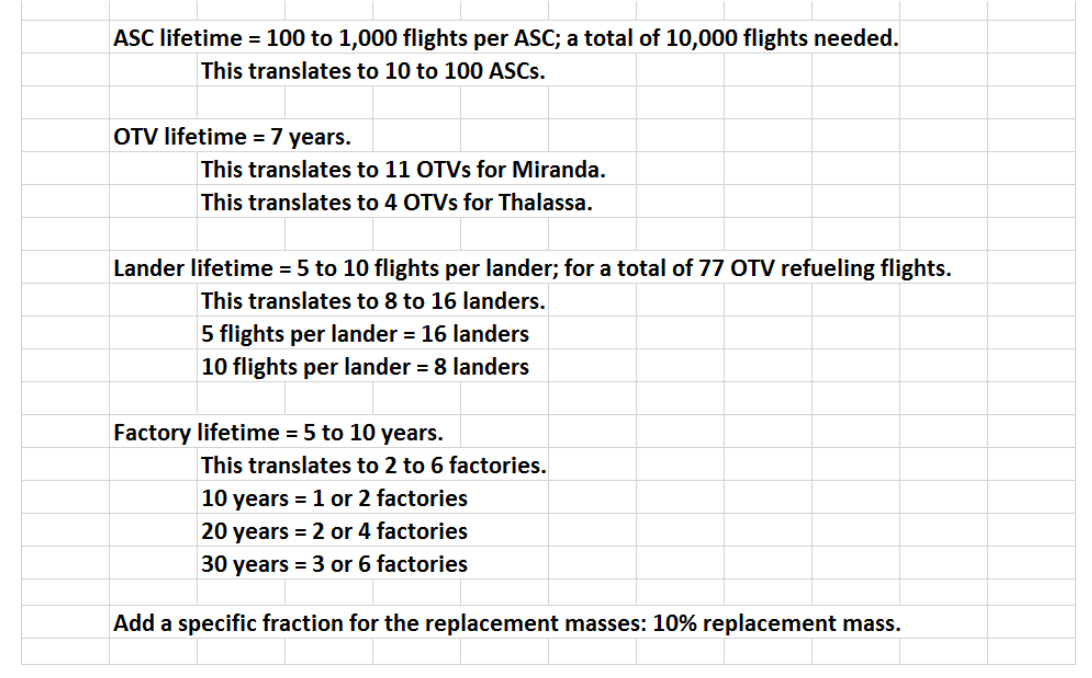




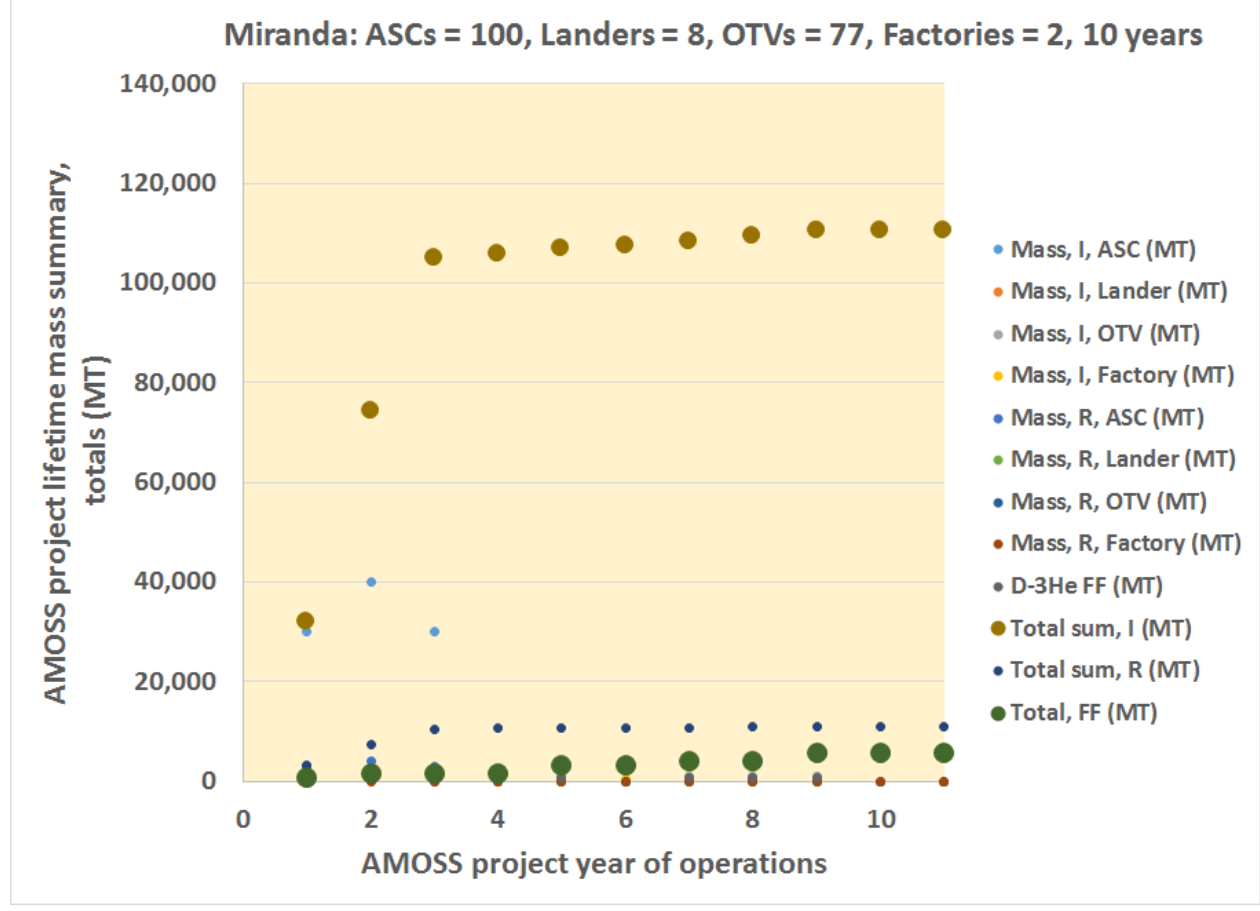

Figure 5. AMOSS on-orbit mass requirements for 10 years of operations, nominal case.

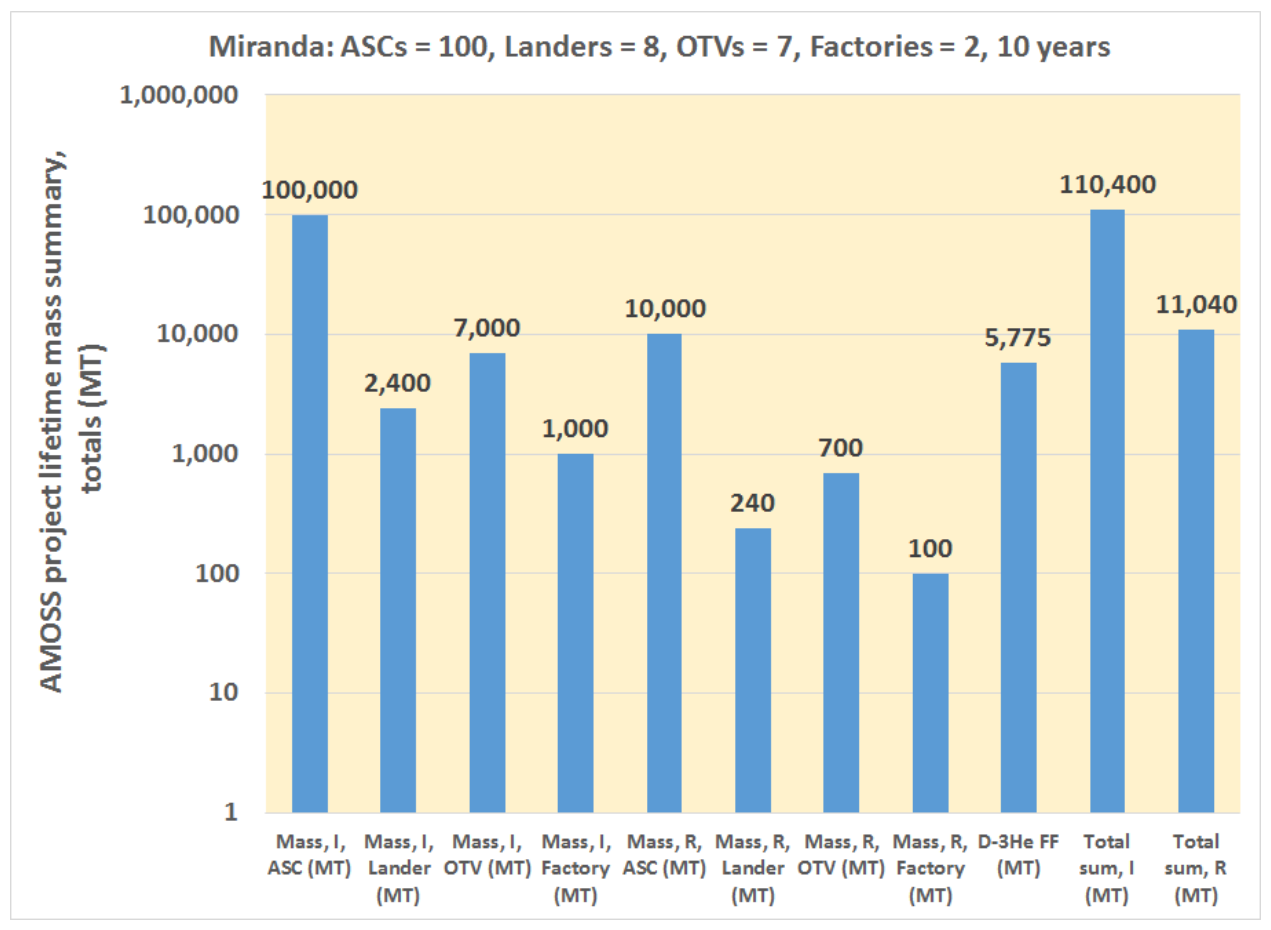

Figure 6. AMOSS on-orbit mass requirements for 10 years of operations, total vehicle masses, nominal case. 


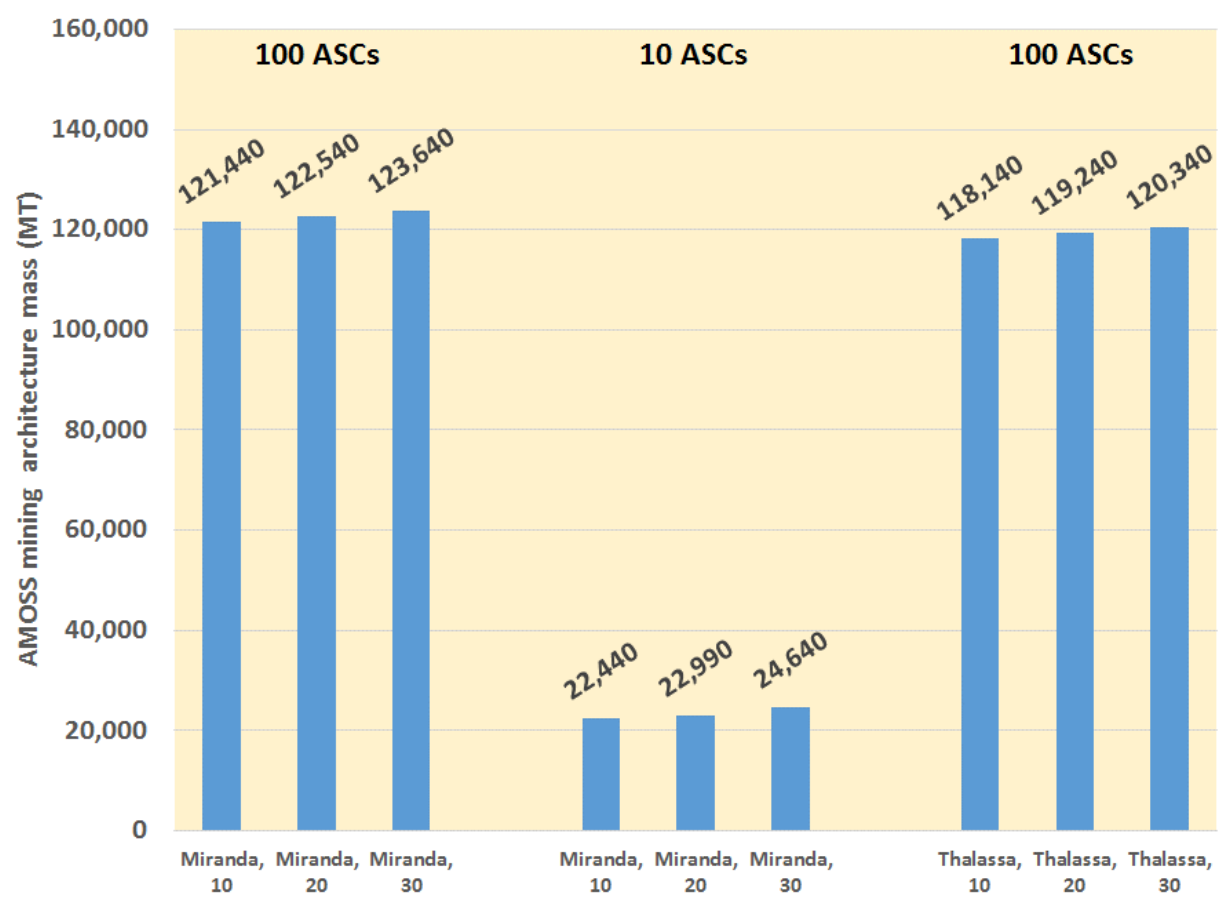

Figure 7. AMOSS mining architecture masses: Miranda with 100 and 10 ASCs and Thalassa with 100 ASCs.

\section{B. Science and prospecting mission options}

Before the AMOSS operations begin, a survey of the planet's moons should be conducted. The survey would be for moon science and prospecting to find the best location for water ice mining. With a nuclear electric propulsion OTV, the power source would provide high power for science instruments. These instruments would include radars that would penetrate the ices of the moons and determine their depth and other spectrometers would help determine the moon's icy composition.

In the overall mission design, there would be a central or centric moon all of the operations. All of the OTV flights would originate at the centric moon. Each OTV would carry a lander into orbit about each moon; the round trip lander flight would carry a $1 \mathrm{MT}$ science and prospecting payload to the surface and back to orbit. There was one additional lander for the large propellant processing factory. A 50 MT propellant processing factory would be landed on the centric moon. The factory would be emplaced there and remain on the surface. The factory would process the water ices on the centric moon and provide hydrogen for the OTV main propulsion and oxygen and hydrogen for the landers.

After a science and prospecting lander had completed its surface visit, it would return to orbit and the OTV would carry it back to the centric moon. The OTV and lander would be refueled in orbit about the centric moon. Since there are 5 moons at Uranus, there would be 4 OTVs for Uranus. Similarly, as there are 8 major moons at Neptune, there were 7 OTVs for those moons. 
A set of interorbital low thrust transfer delta- $\mathrm{V}$ maps were computed for Uranus' and Neptune's moons. The delta-V maps are presented in Tables VII and VIII. These maps allow rapid identification of the delta-V values needed for inter-moon transportation.

At Uranus, using Umbriel as the centric moon enabled the lowest total transportation mass. For Neptune, Larissa provided the lowest total transportation mass. In all cases, the lander Isp was 480 seconds and the OTV power source had a reactor specific mass or alpha of $10 \mathrm{~kg} / \mathrm{kWe}$, and reactor power level was $10 \mathrm{MWe}$. The OTV Isp was 5,000 seconds.

Table VII. Interorbital delta-V map for Uranus' moons

\begin{tabular}{|c|c|c|c|c|c|c|}
\hline Moon & Miranda & Ariel & Umbriel & Titania & Oberon & Sum $(\mathrm{km} / \mathrm{s})$ \\
\hline Miranda & 0.000 & 2.950 & 4.224 & 6.177 & 7.136 & 20.487 \\
\hline Ariel & 2.950 & 0.000 & 1.433 & 3.479 & 4.465 & 12.328 \\
\hline Umbriel & 4.224 & 1.433 & 0.000 & 2.046 & 3.032 & 10.735 \\
\hline Titania & 6.177 & 3.479 & 2.046 & 0.000 & 0.986 & 12.688 \\
\hline Oberon & 7.136 & 4.465 & 3.032 & 0.986 & 0.000 & 15.619 \\
\hline Sum $(\mathrm{km} / \mathrm{s})$ & 20.487 & 12.328 & 10.735 & 12.688 & 15.619 & \\
\hline & & & & & & \\
\hline
\end{tabular}

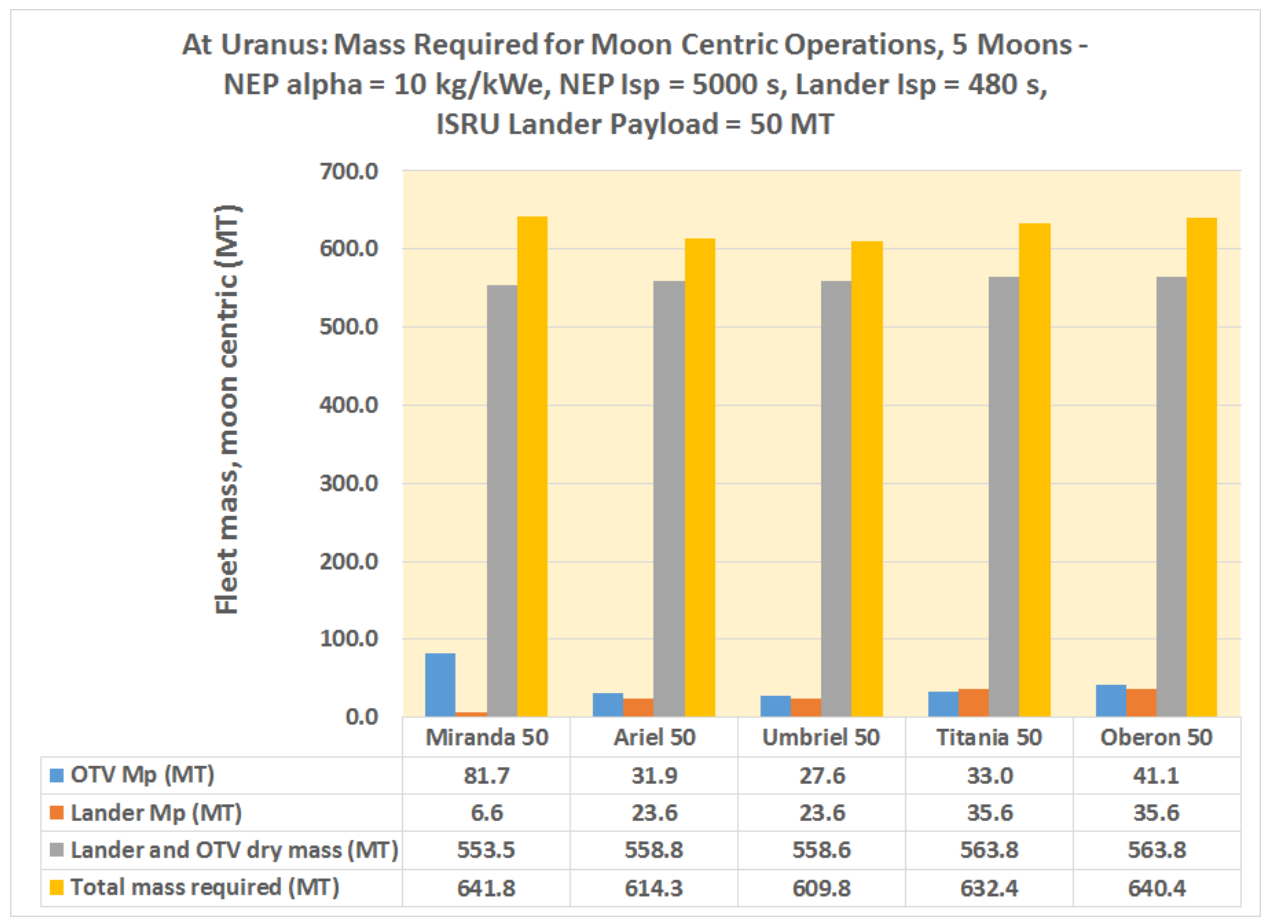

Figure VIII. Mass required for centric moon operations: Uranus 
Table VIII. Interorbital delta-V map for Neptune's moons

\begin{tabular}{|c|c|c|c|c|c|c|c|c|c|c|}
\hline Moon & Naiad & Thalassa & Despina & Galatea & Larissa & S/2004 & Proteus & Triton & Nereid & Sum $(k m / s)$ \\
\hline Naiad (NIII) & 0.00 & 2.96 & 3.14 & 4.01 & 5.26 & & 8.91 & 15.15 & 21.59 & 61.02 \\
\hline $\begin{array}{l}\text { Thalassa } \\
\text { (NIV) }\end{array}$ & 2.96 & 0.00 & 0.56 & 2.36 & 4.09 & & 8.12 & 14.59 & 21.18 & 53.86 \\
\hline & & & & & & & & & & \\
\hline Despina (NV) & 3.14 & 0.56 & 0.00 & 1.81 & 3.54 & & 7.57 & 14.04 & 20.64 & 51.29 \\
\hline Galatea (NVI) & 4.01 & 2.36 & 1.81 & 0.00 & 1.73 & & 5.76 & 12.23 & 18.83 & 46.73 \\
\hline & & & & & & & & & & \\
\hline Larissa (NVII) & 5.26 & 4.09 & 3.54 & 1.73 & 0.00 & & 4.04 & 10.50 & 17.10 & 46.24 \\
\hline & & & & & & & & & & \\
\hline S/2004 N1 & & & & & & 0.00 & & & & 0.00 \\
\hline & & & & & & & & & & \\
\hline $\begin{array}{l}\text { Proteus } \\
\text { (NVIII) }\end{array}$ & 8.91 & 8.12 & 7.57 & 5.76 & 4.04 & & 0.00 & 6.47 & 13.07 & 53.94 \\
\hline Triton (NI) & 15.15 & 14.59 & 14.04 & 12.23 & 10.50 & & 6.47 & 0.00 & 6.61 & 79.58 \\
\hline & & & & & & & & & & \\
\hline Nereid (NII) & 21.59 & 21.18 & 20.64 & 18.83 & 17.10 & & 13.07 & 6.61 & 0.00 & 119.02 \\
\hline & & & & & & & & & & \\
\hline & & & & & & & & & & \\
\hline Sum $(\mathrm{km} / \mathrm{s})$ & 61.02 & 53.86 & 51.29 & 46.73 & 46.24 & 0.00 & 53.94 & 79.58 & 119.02 & \\
\hline & & & & & & & & & & \\
\hline
\end{tabular}

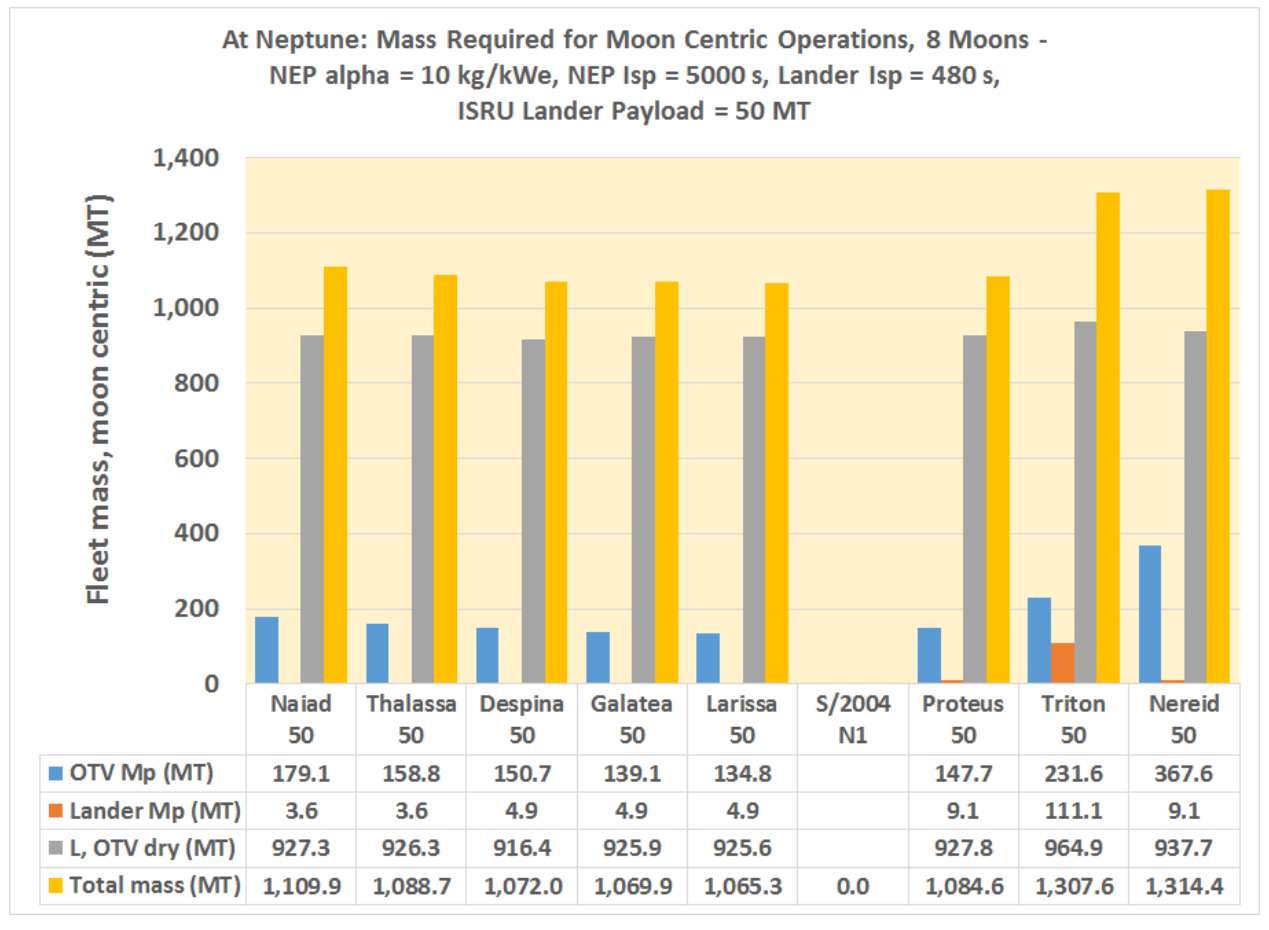

Figure 8. Mass required for centric moon operations: Neptune 


\section{Concluding Remarks}

Atmospheric mining in the outer solar system has many significant benefits. The use of ISRU in the outer solar system will entail wresting nuclear fuels from Uranus and or Neptune. Using outer planet moon bases for mining the propellants for OTVs and landers is an important option. Storing the AMOSS nuclear fuels away from the atmosphere will minimize the potential for unanticipated deorbiting of the orbiting storage facility. Using the moons for storage of the nuclear fuels and base of operations for OTV refueling is an excellent option. Though the gravity of these moons are much lower than that of Earth, that gravity will assist in any processes for mining and fuel processing. The $10 \mathrm{MWe}$ power levels for the OTV seems best for providing a relatively short moon-to-planet trip time. The OTVs and landers will rendezvous near the escape condition of the small moon, shortening the trip time for the OTV (eliminating the need to spiral into low moon orbit). Larger landers (of 200 MT payloads) are more attractive than small landers, as the large landers require fewer flights to resupply the OTVs with fuel. The OTV trip times may be too long for effective use of the more distant outer planet moons. Moons that are closer to the planet may be required. Generally, the smaller moon closer to the planet are more mass efficient, requiring smaller OTV and smaller landers.

Both Uranus and Neptune transportation system mass estimates are presented in Figures 3 for Uranus, and Figures 4 for Neptune. In each figure, the major moons are noted and the OTV and lander masses are shown. Of the five major moons of Uranus, the moons closest to the planet required the lowest transportation system mass. For Uranus, Miranda has the lowest transportation system mass. The lander mass has a strong influence on the overall mass. The result is similar for the 8 major moons of Neptune. The transportation system for Thalassa has the lowest overall mass of the 8 Neptune moon destinations. Thalassa is the moon with the lowest gravity, allowing the lander to be much smaller than any of the 4 cases. Therefore, increasing the lander Isp or using a moon with reduced gravity has a powerful effect on the overall mass.

The transportation masses for all of the major moons of Uranus and Neptune were investigated. At both Uranus and Neptune, the smaller moons near the planet had the lowest transportation masses. While this is an important result, it is also critically important to address the need for additional gravity for processing of fuels and propellants. Centrifuges (or other equally effective technologies) to separate the water ice and rocky feed stocks from the outer planet moon's surface will likely be needed. The low gravity of the outer planet moons will not be sufficient to process the ISRU related materials and allow efficient production of OTV and lander propellants. All of the outer planet moons have such low gravity levels that some added artificial gravity to assist the ISRU processes will be very important for the overall architecture's success.

The overall architecture masses were estimated for a range of operational schedules. The delivery schedules included 7 year lifetime for nuclear electric propulsion OTVs and addressed the major architecture components: the atmospheric mining ASCs, the OTVs, the landers, and the in-space factories. For the 10, 20, and 30 year operational mining time, the total masses needed were 118,000 MT to $123,000 \mathrm{MT}$. These results required the use of $100 \mathrm{ASC}$ to complete the atmospheric mining. Using 100 ASCs required each to complete 100 round trip mining flights from orbit to the planet's atmosphere. If only 10 ASCs were to be used, each would have to perform 1000 flights; based on historical space flight experience, this number of flights seems unfeasible. For the 10 year mining operational plan, approximately 12,000 MT per year would have to be delivered to Uranus. If the mining time can be allowed to extend to 30 years, the mass delivered per year would be an average of 4,000 MT per year. 
Science and prospecting missions can also be conducted with an OTV and lander fleet. The OTVs would operate from a centric moon and with an ISRU factory, provide refueling of the OTVs and the landers and enable multiple round trip flights to the planets' moons. An extensive number of science and prospecting measurement would be possible with the high power, $10 \mathrm{MWe}$ electric nuclear power supply aboard the OTVs.

Further optimizations and creative usage of propulsion technologies will likely lead to great improvements in the transportation systems and reduce its cost and mass. The exploration of the outer planets and their ultimate use in powering future fusion powered space vehicles will allow unlimited options for solar system exploration, and ultimately, flights to the stars. 
Appendix A: AMOSS operations masses at Miranda (Uranus): 10, 20 and 30 years, 100 ASCs

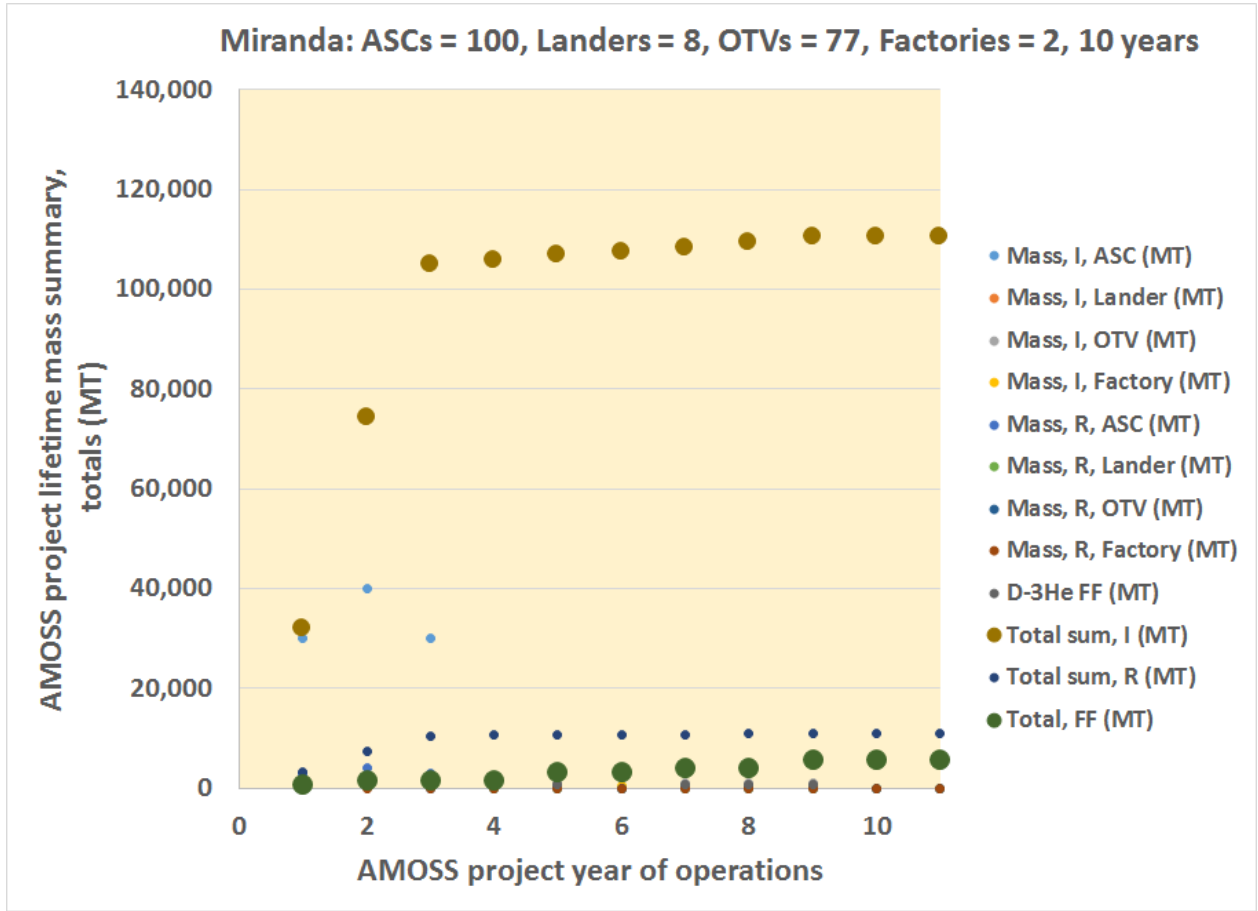

Figure A1. AMOSS on-orbit mass requirements for 10 years of operations, Miranda, 100 ASCs.

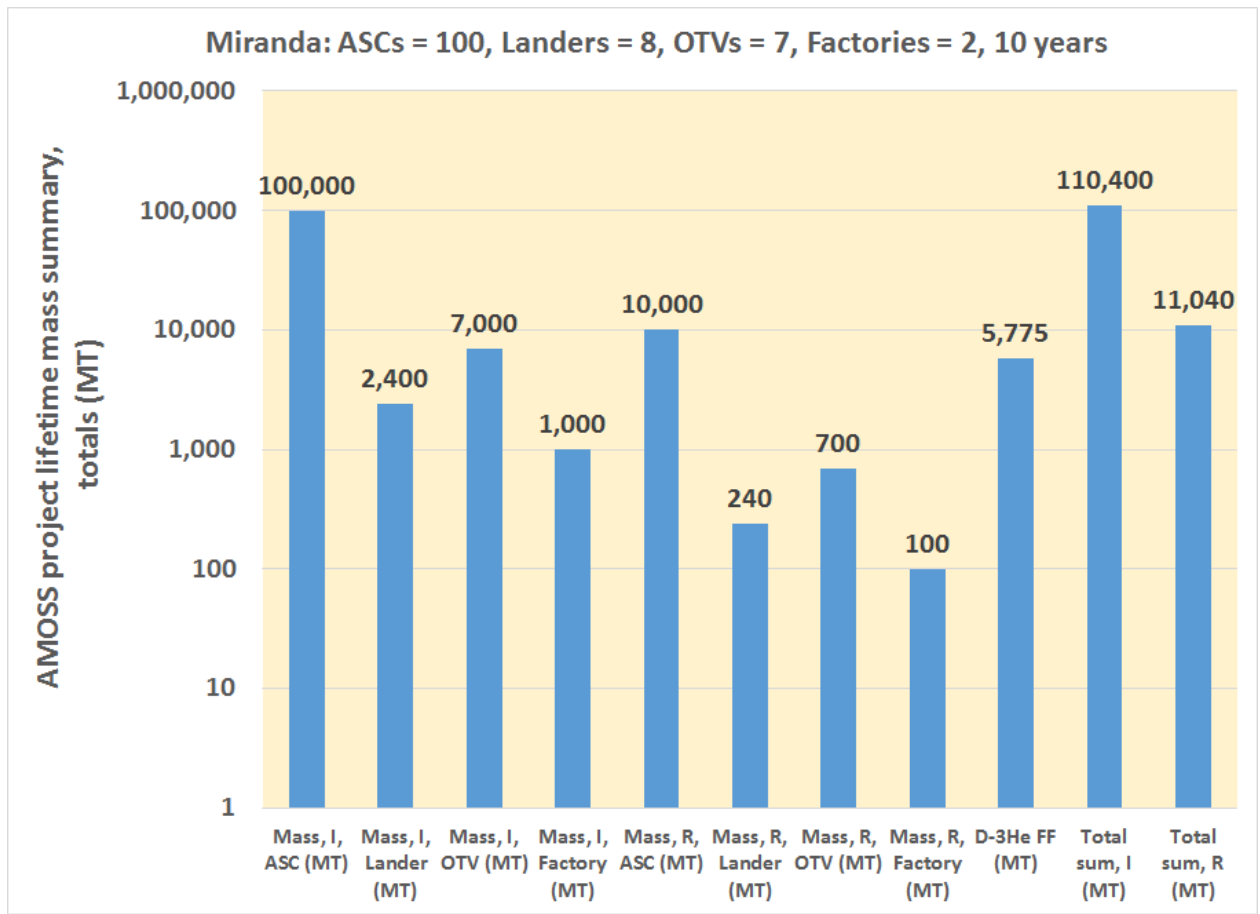

Figure A2. AMOSS on-orbit mass requirements for 10 years of operations, total vehicle masses, Miranda, 100 ASCs. 


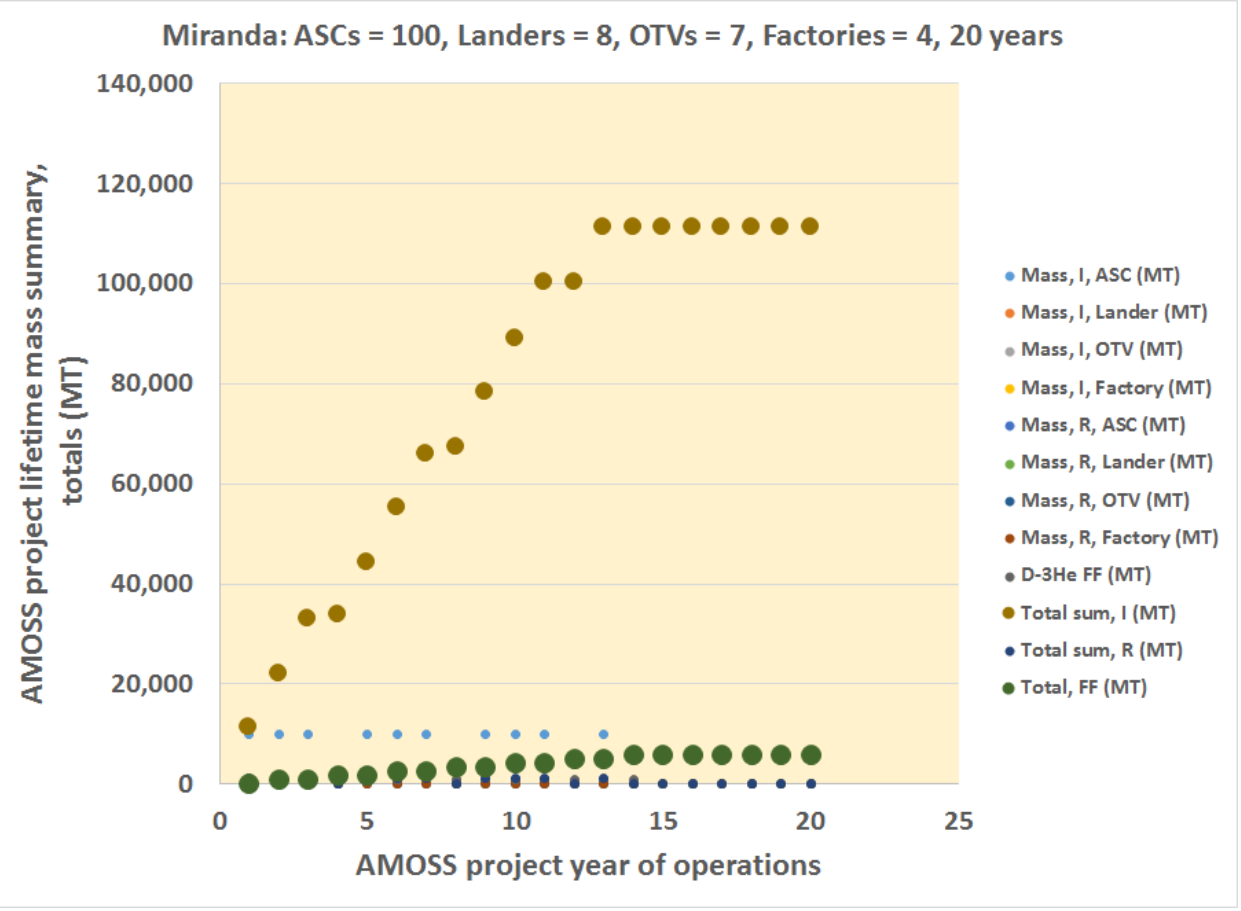

Figure A3. AMOSS on-orbit mass requirements for 20 years of operations, Miranda, 100 ASCs.

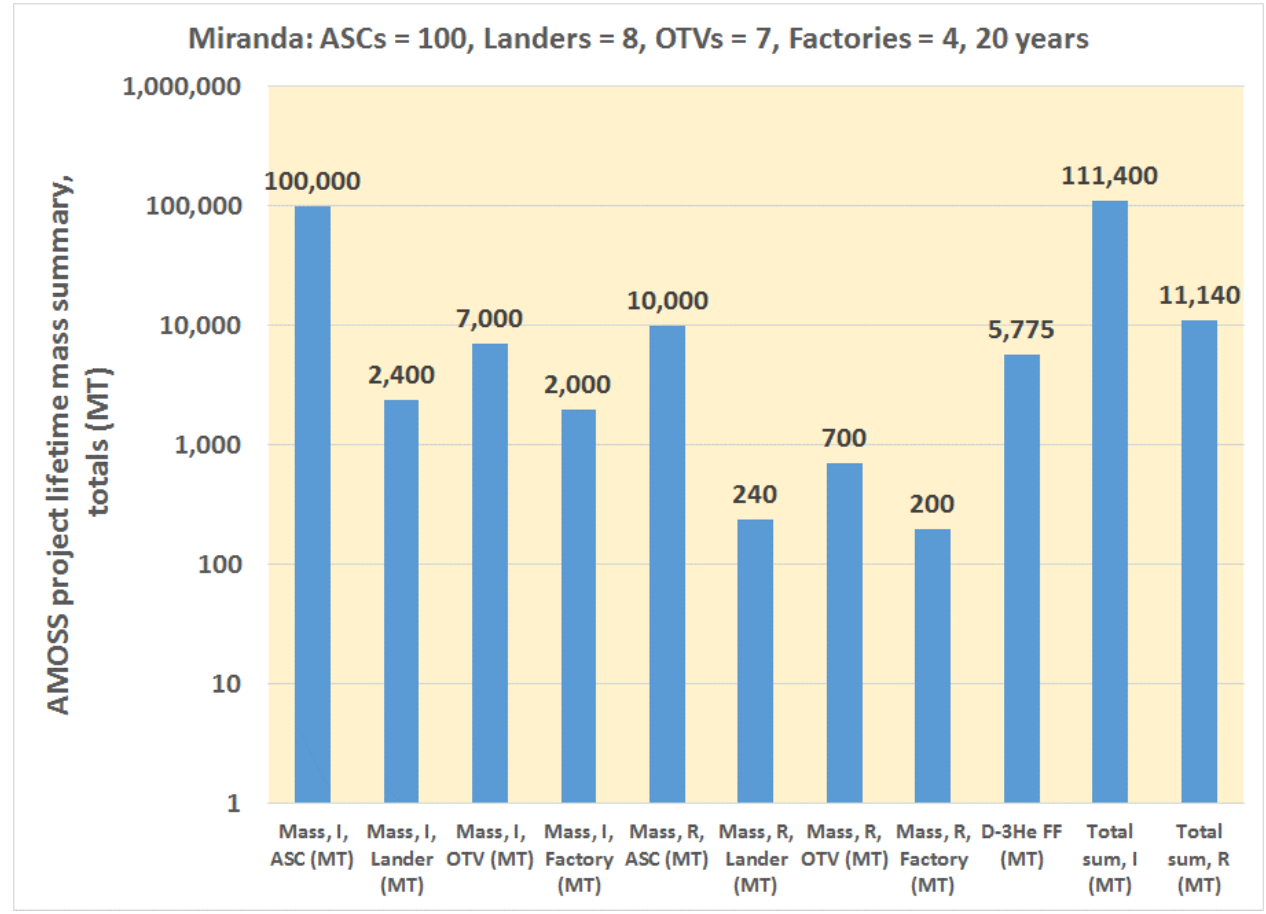

Figure A4. AMOSS on-orbit mass requirements for 20 years of operations, total vehicle masses, Miranda, 100 ASCs. 


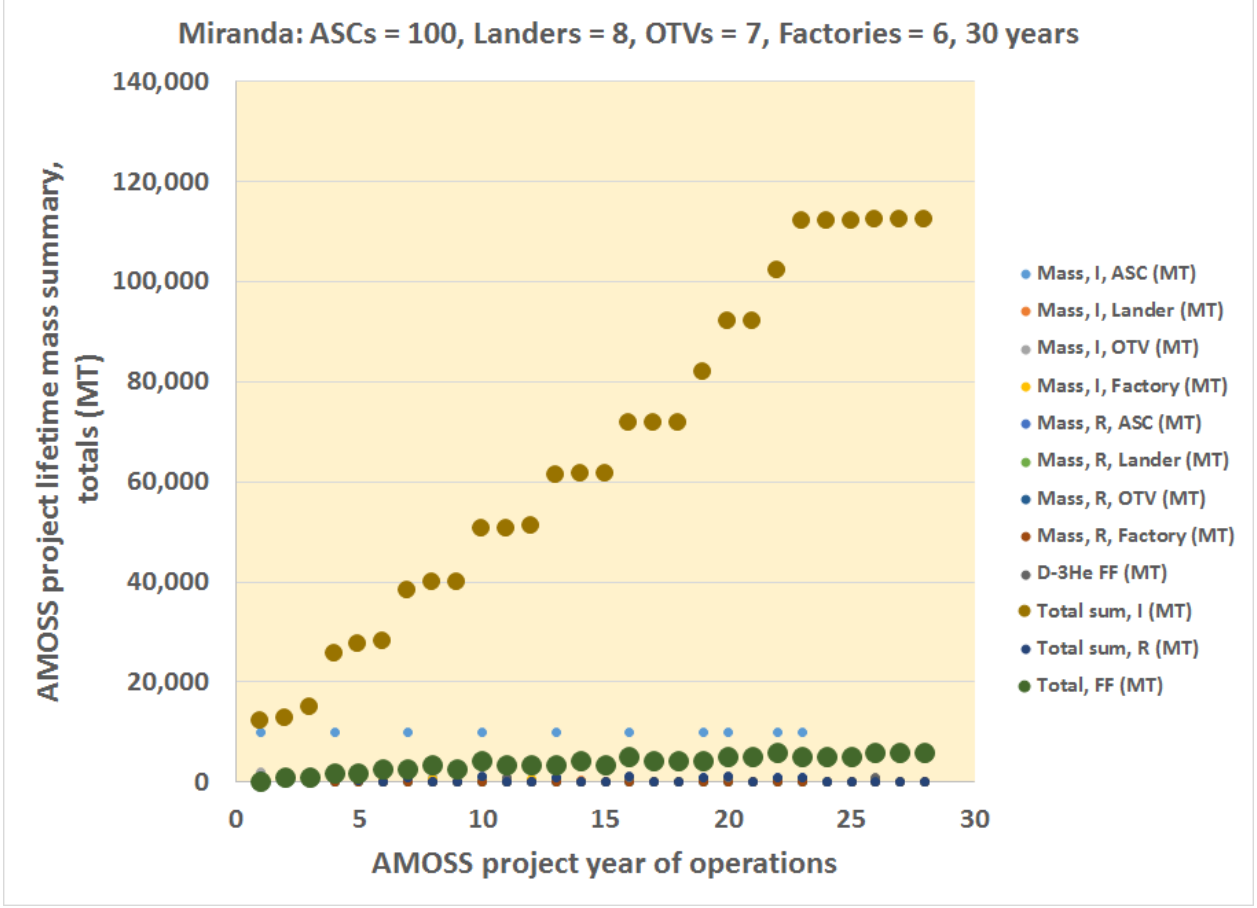

Figure A5. AMOSS on-orbit mass requirements for 30 years of operations, Miranda, 100 ASCs.

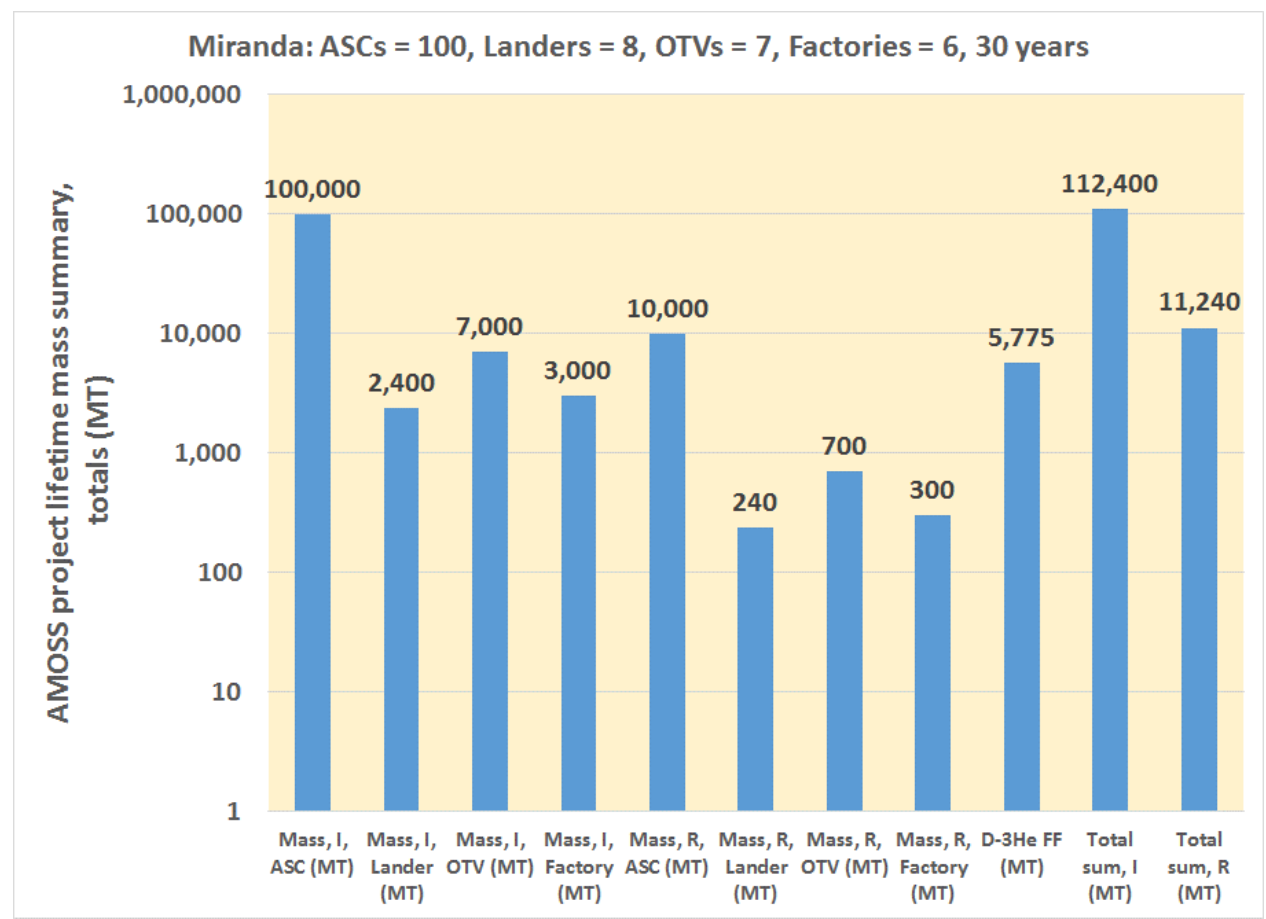

Figure A6. AMOSS on-orbit mass requirements for 30 years of operations, total vehicle masses, Miranda, 100 ASCs. 
Appendix B: AMOSS operations masses at Miranda (Uranus): 10, 20 and 30 years, 10 ASCs

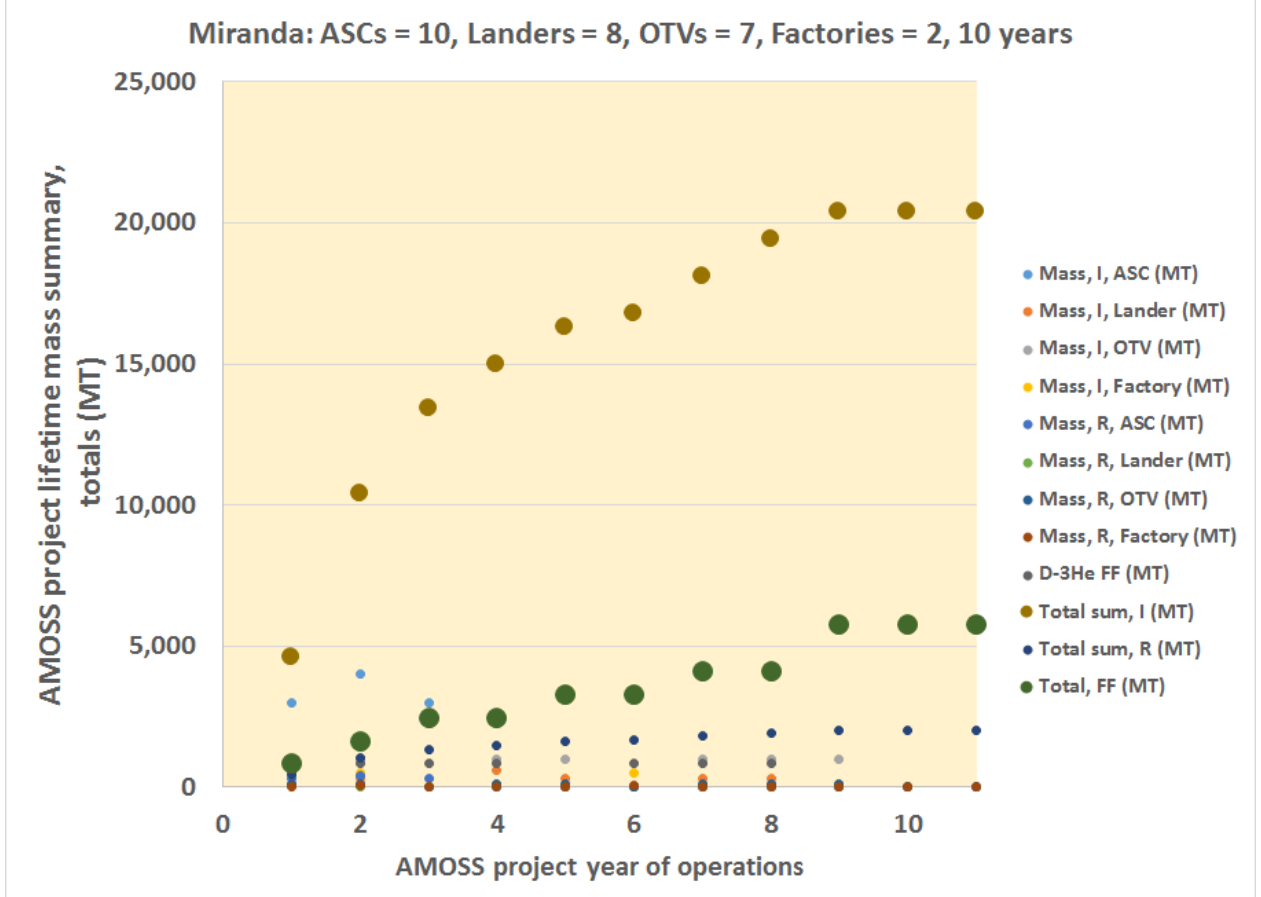

Figure B1. AMOSS on-orbit mass requirements for 10 years of operations, Miranda, 10 ASCs.

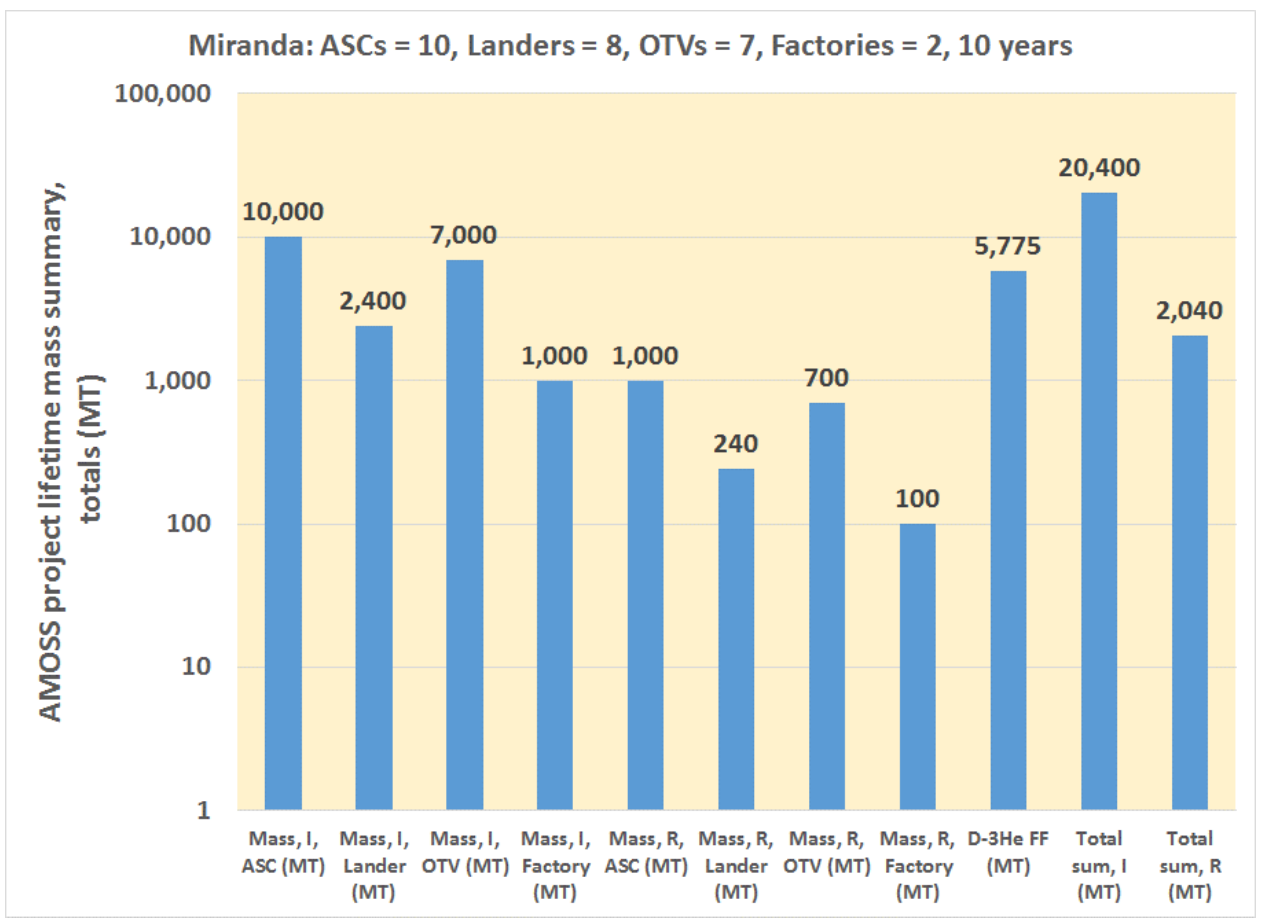

Figure B2. AMOSS on-orbit mass requirements for 10 years of operations, total vehicle masses, Miranda, 10 ASCs. 


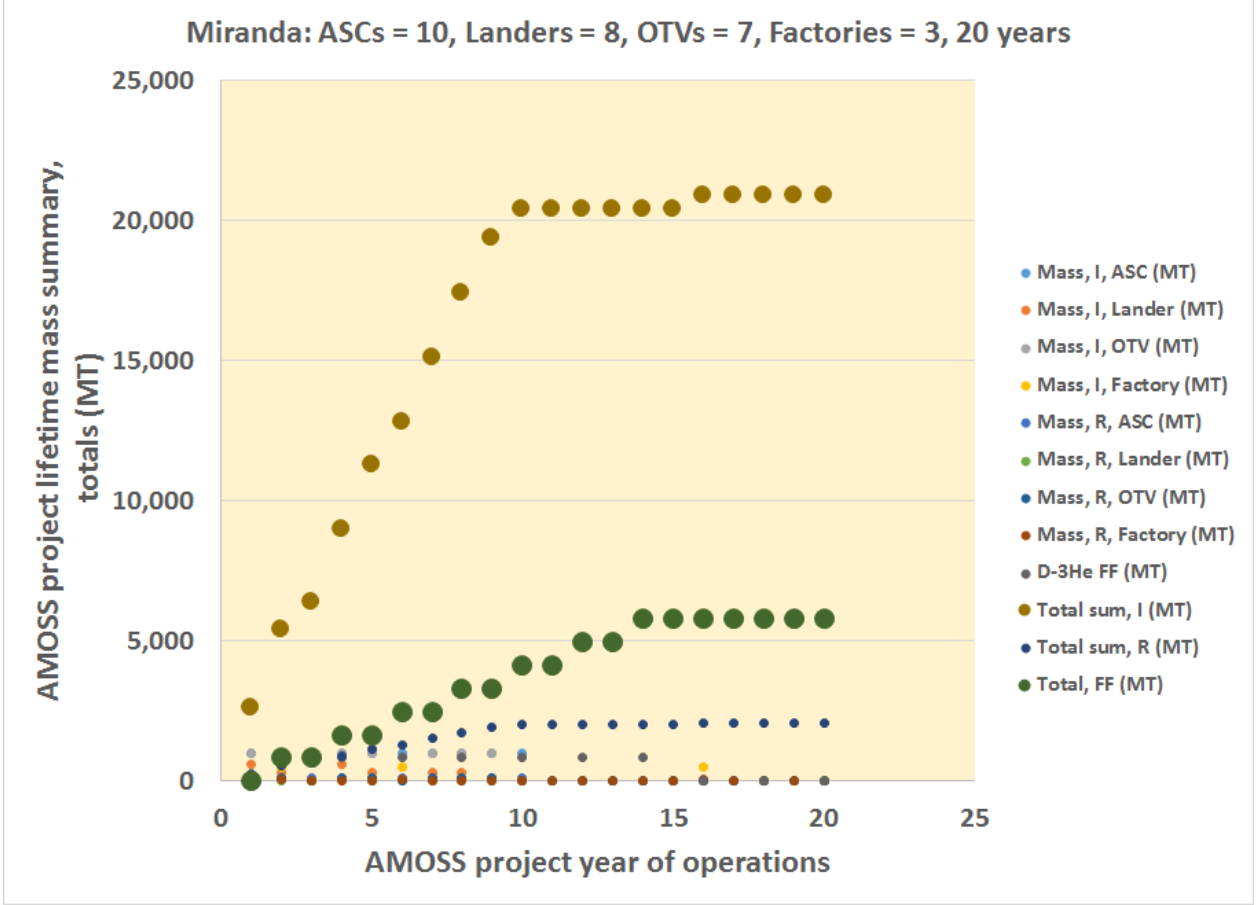

Figure B3. AMOSS on-orbit mass requirements for 20 years of operations, Miranda, 10 ASCs.

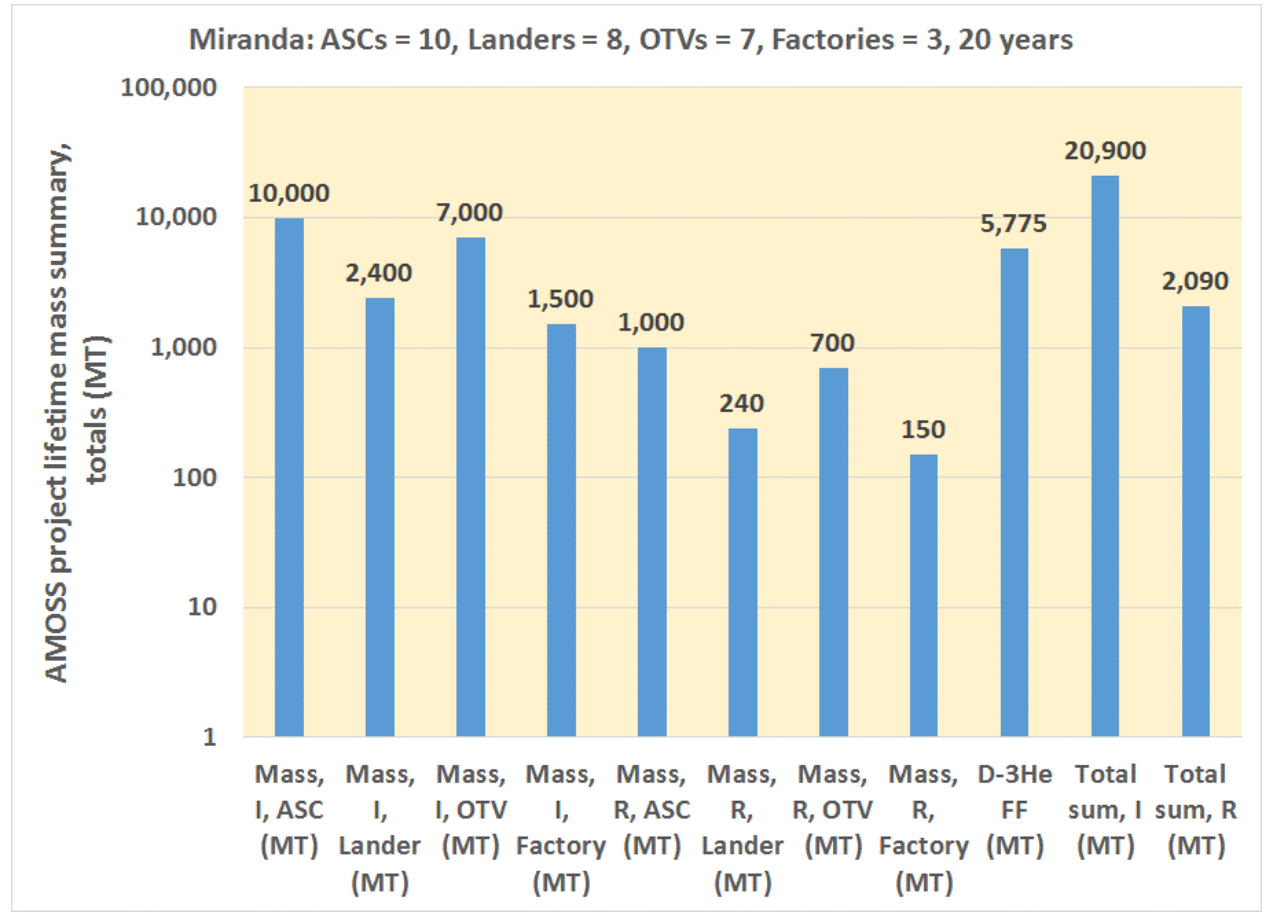

Figure B4. AMOSS on-orbit mass requirements for 20 years of operations, total vehicle masses, Miranda, 10 ASCs 


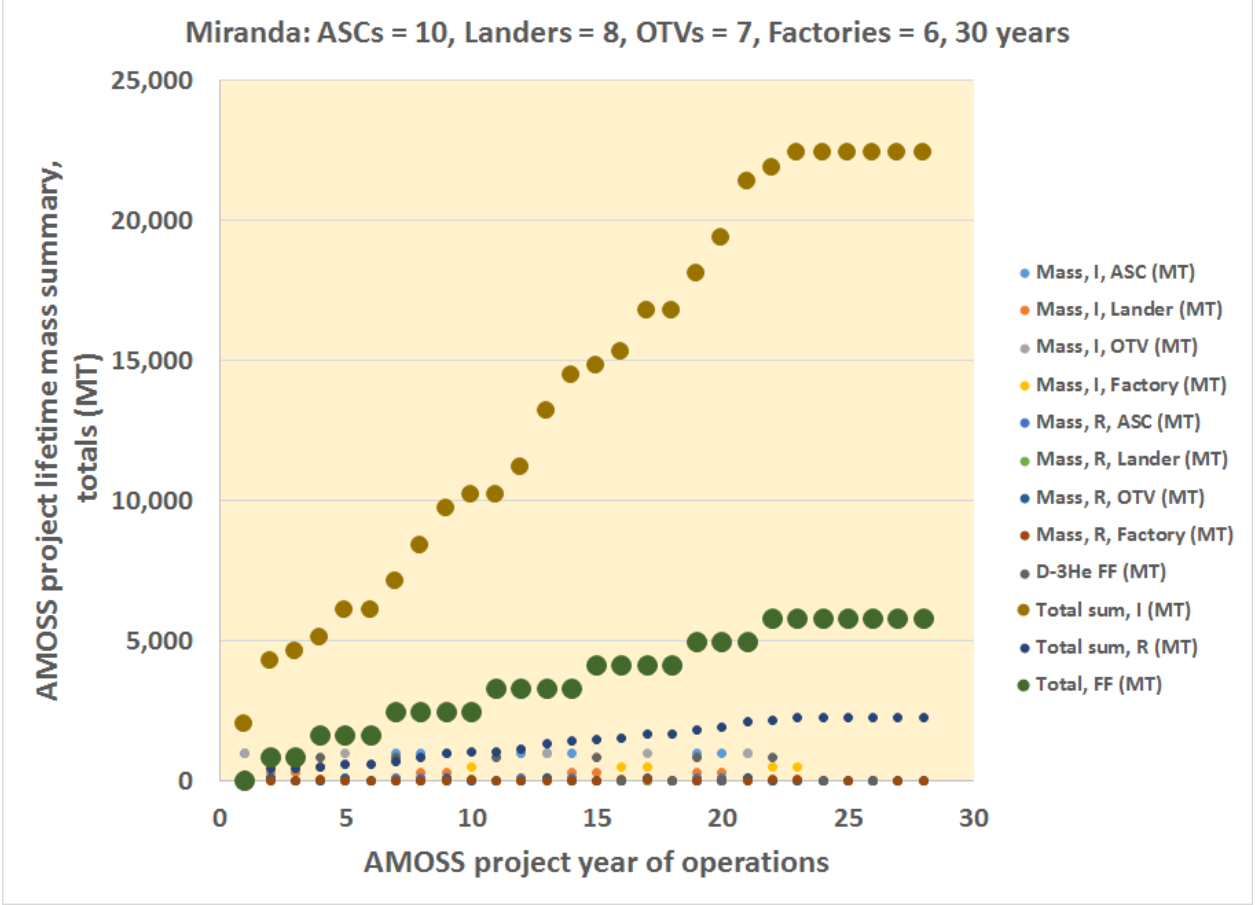

Figure B5. AMOSS on-orbit mass requirements for 30 years of operations, Miranda, 10 ASCs

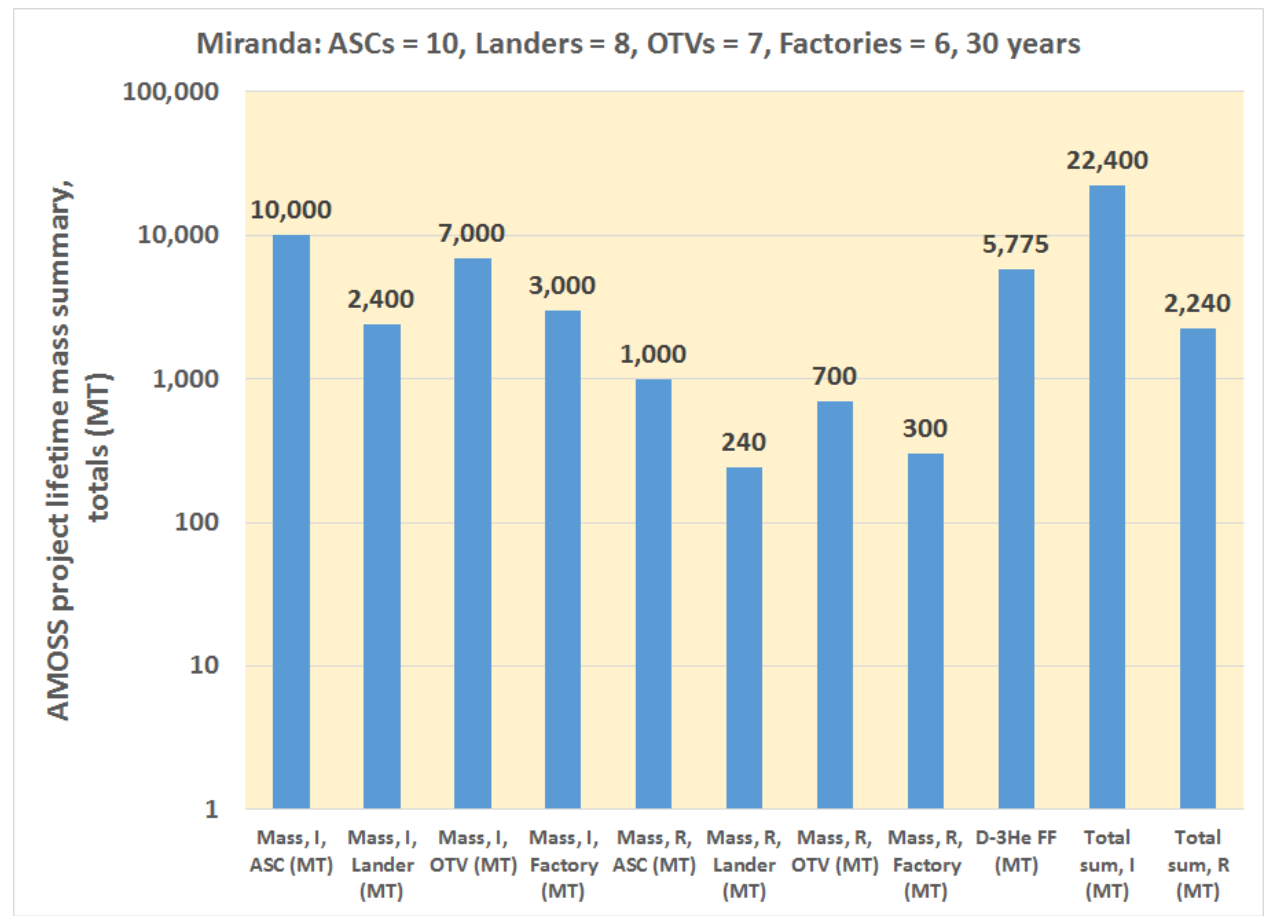

Figure B6. AMOSS on-orbit mass requirements for 30 years of operations, total vehicle masses, Miranda, 10 ASCs 
Appendix C: AMOSS operations masses at Thalassa (Neptune): 10, 20 and 30 years, 100 ASCs

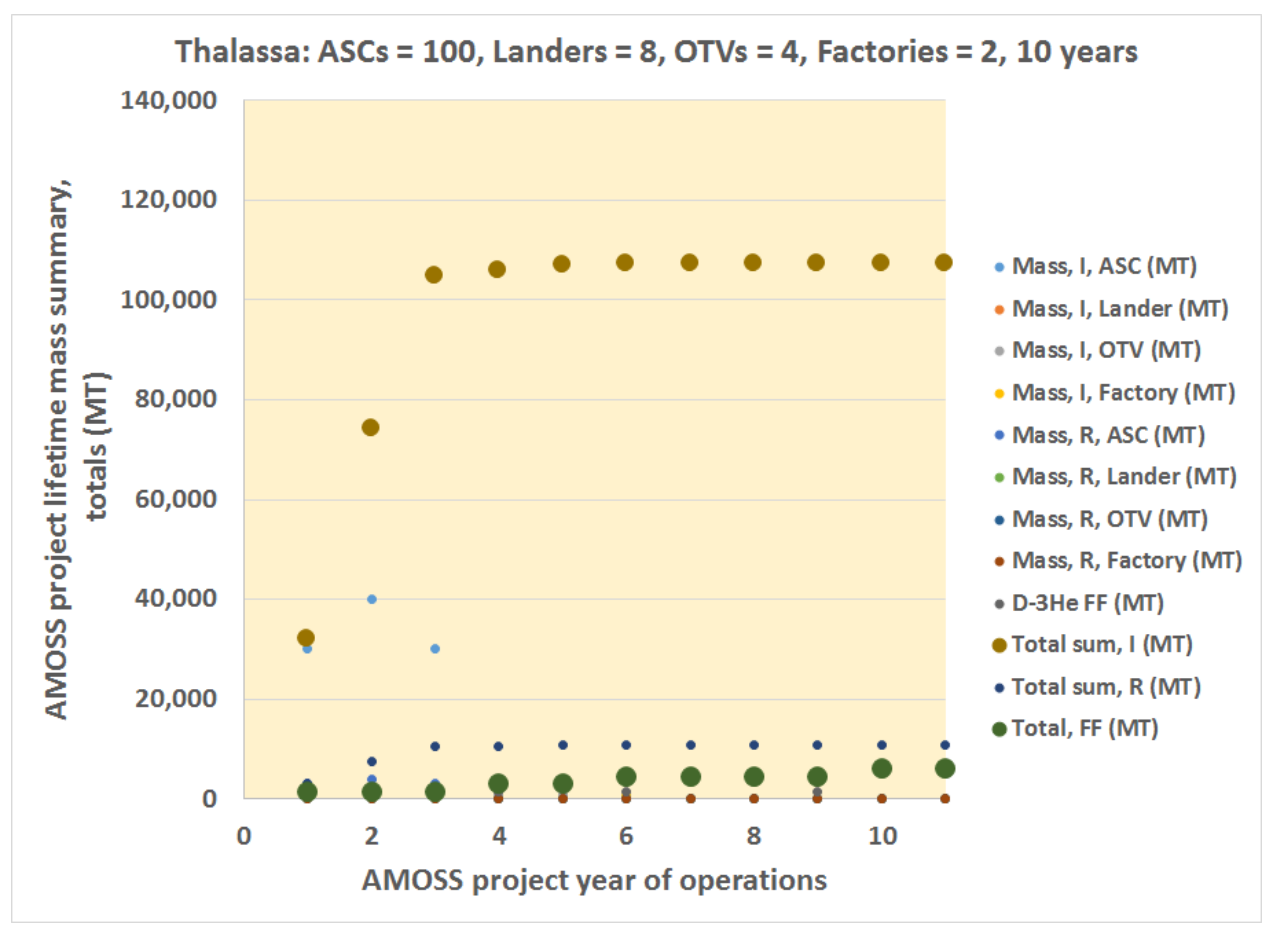

Figure C1. AMOSS on-orbit mass requirements for 10 years of operations, Thalassa, 100 ASCs.

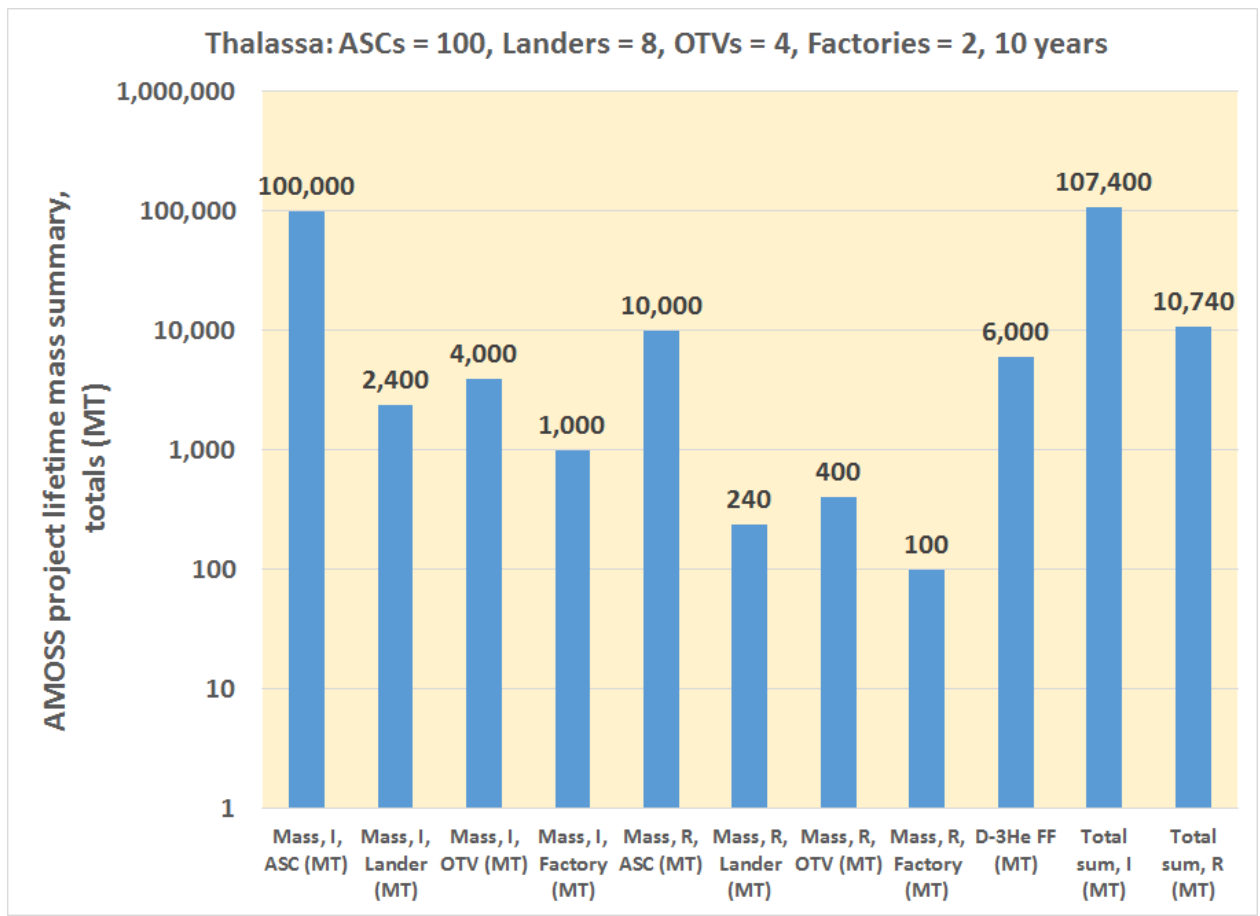

Figure C2. AMOSS on-orbit mass requirements for 10 years of operations, total vehicle masses, Thalassa, 100 ASCs. 


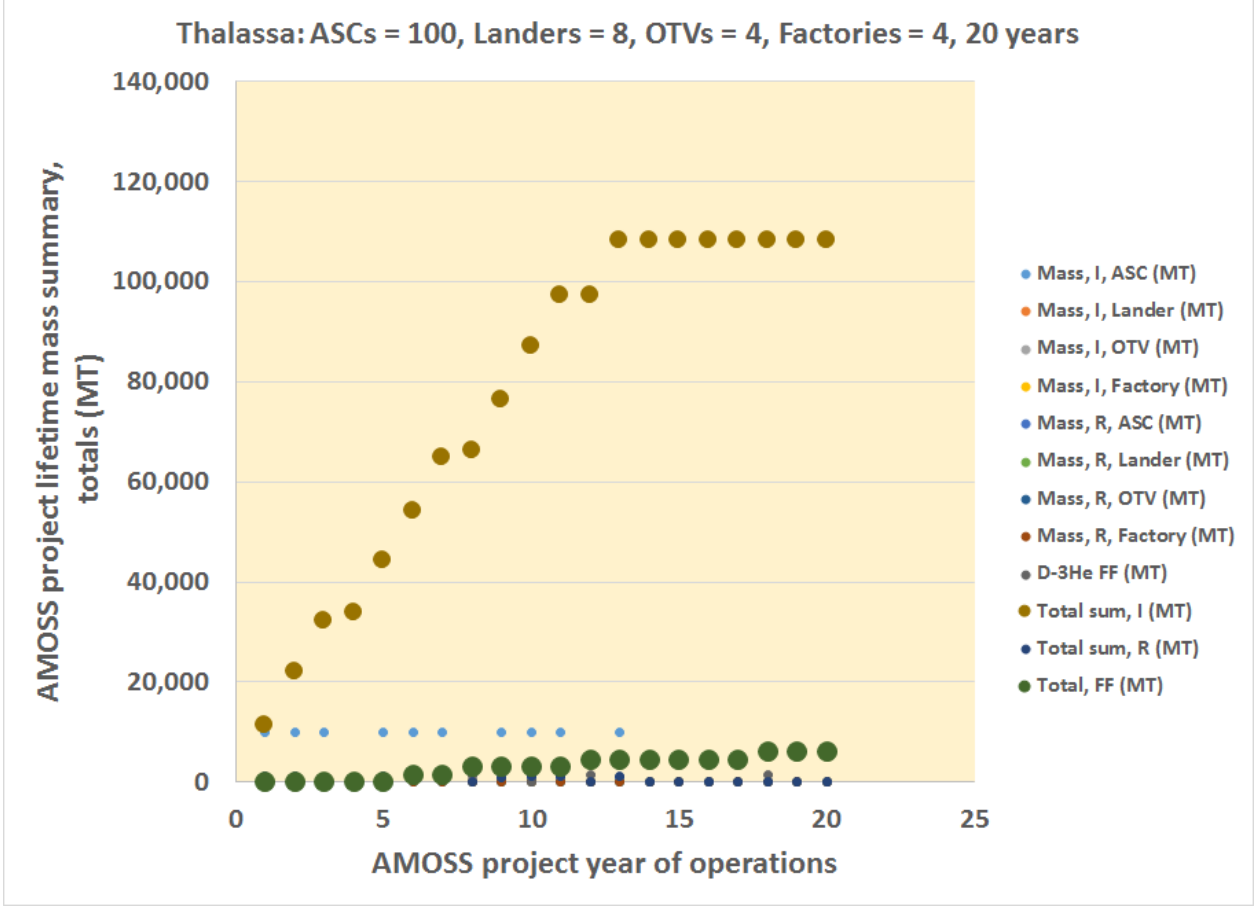

Figure C3. AMOSS on-orbit mass requirements for 20 years of operations, Thalassa, 100 ASCs..

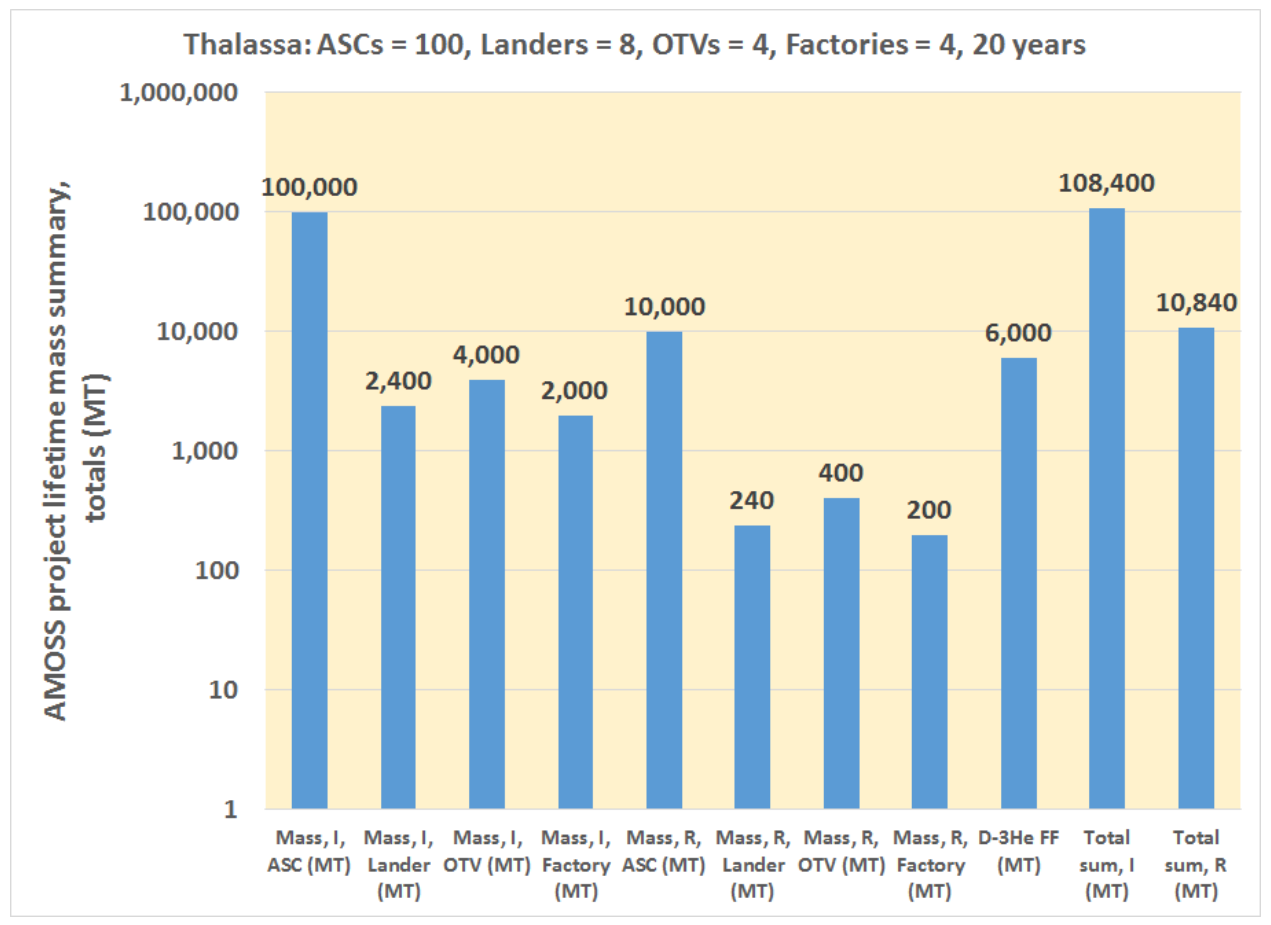

Figure C4. AMOSS on-orbit mass requirements for 20 years of operations, total vehicle masses, Thalassa, 100 ASCs. 


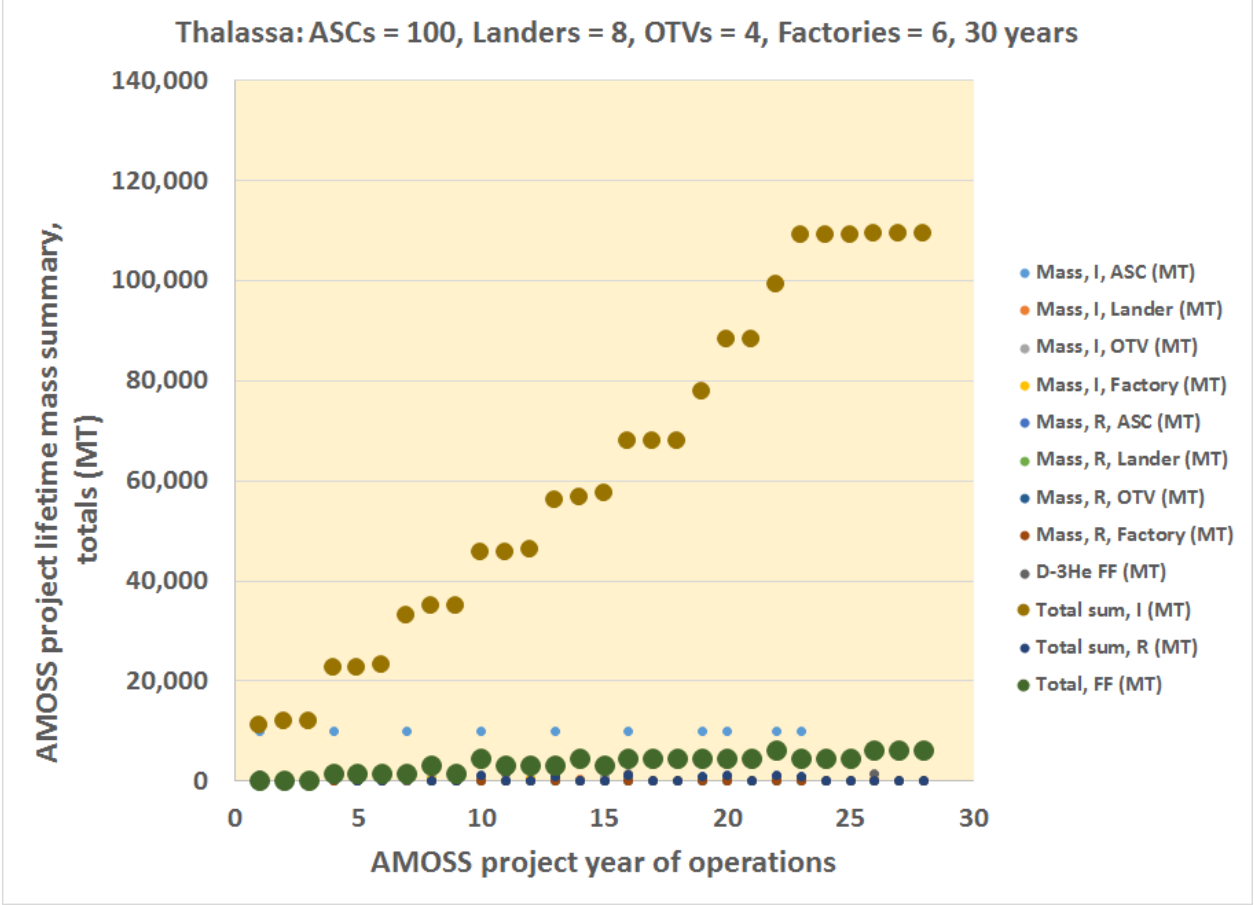

Figure C5. AMOSS on-orbit mass requirements for 30 years of operations, Thalassa, 100 ASCs.

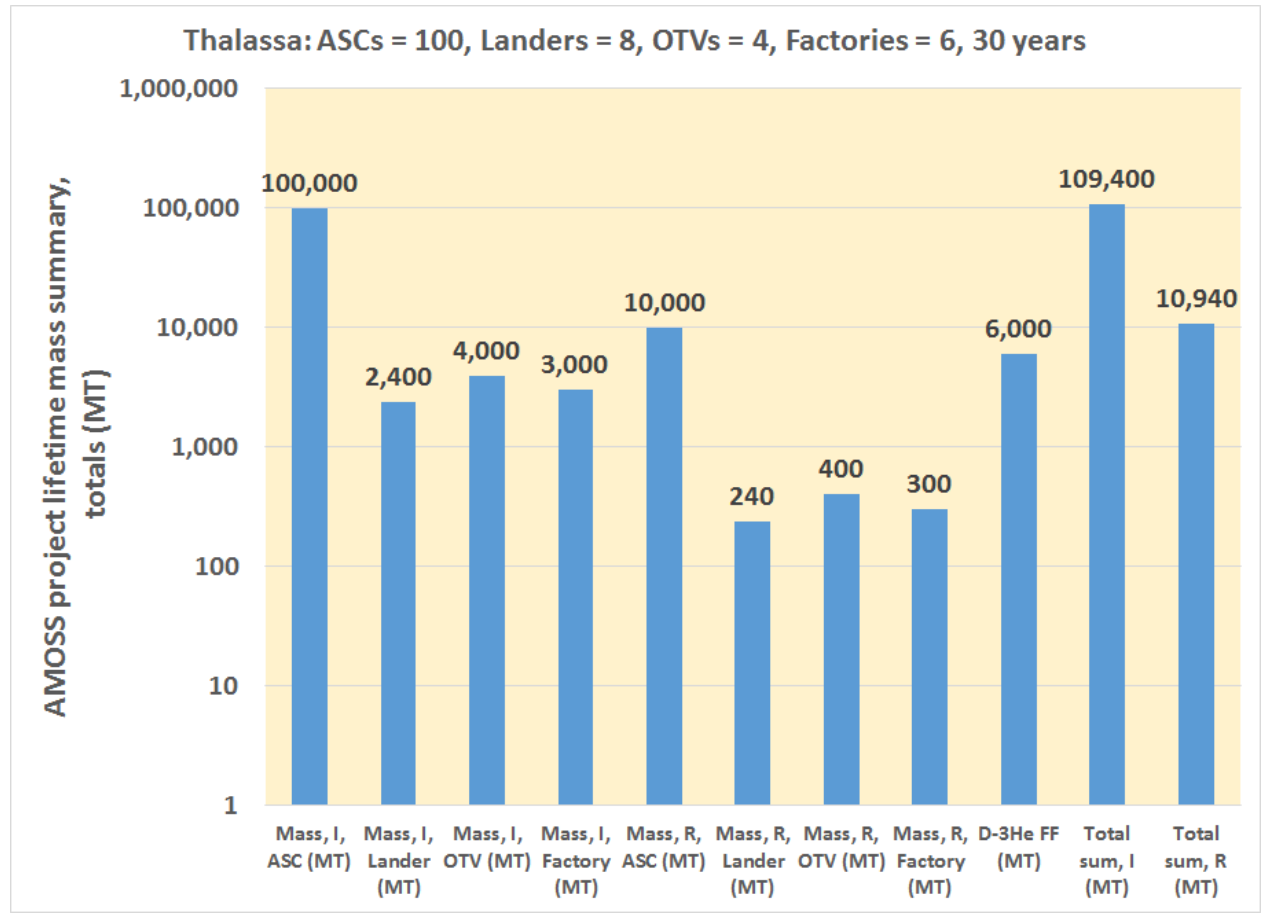

Figure C6. AMOSS on-orbit mass requirements for 30 years of operations, total vehicle masses, Thalassa, 100 ASCs. 


\section{References}

1) Palaszewski, B., "Atmospheric Mining in the Outer Solar System: Outer Planet In-Space Bases and Moon Bases for Resource Processing," AIAA 2017-4937, July 2017.

2) Palaszewski, B., "Atmospheric Mining in the Outer Solar System: Orbital Transfer Vehicles and Outer Planet Moon Base Options," AIAA 2016-4889, July 2016.

3) Palaszewski, B., "Atmospheric Mining in the Outer Solar System: Aerial Vehicle Mission and Design Issues," AIAA 2015-4078, July 2015.

4) Palaszewski, B., "Atmospheric Mining in the Outer Solar System: Aerial Vehicle Reconnaissance and Exploration Options,” AIAA 2014-3819, July 2014.

5) Palaszewski, B., “Atmospheric Mining in the Outer Solar System: Resource Capturing, Exploration, and Exploitation,” AIAA 2013-3765, August 2013.

6) Palaszewski, B., "Atmospheric Mining in the Outer Solar System: Resource Capturing, Storage, and Utilization," AIAA 2012-3742, August 2012.

7) Palaszewski, B., "Atmospheric Mining in the Outer Solar System: Issues and Challenges for Mining Vehicle Propulsion," AIAA 2011-6041, August 2011.

8) Palaszewski, B., "Atmospheric Mining in the Outer Solar System: University Studies of Mining Vehicles and Propulsion,” AIAA 2010-6573, August 2010.

9) Palaszewski, B., "Atmospheric Mining in the Outer Solar System: Mining Design Issues and Considerations," AIAA 2009-4961, August 2009.

10) Palaszewski, B., "Atmospheric Mining in the Outer Solar System: Orbital Transfer Vehicles and Outer Planet Moon Base Options," AIAA 2008-4861, July 2008.

11) Palaszewski, B., "Atmospheric Mining in the Outer Solar System: Mission Scenarios and Options for In-Situ Resource Utilization.” AIAA 2007-5598, July 2007.

12) Palaszewski, B., "Atmospheric Mining in the Outer Solar System: Vehicle Sizing Issues.” AIAA 2006-5222, July 2006.

13) R. Frisbee, “Advanced Space Propulsion for the 21st Century," Journal of Propulsion and Power, Vol. 19, No. 6, Nov-Dec 2003.

14) Dunn, Bruce P., "High-Energy Orbit Refueling for Orbital Transfer Vehicles," Journal of Spacecraft and Rockets Volume. 24, No. 6, 1987, pp. 518-522.

15) Noca, M.; Polk, J. E. "Ion Thrusters And LFAs For Outer Planet Exploration, “IAF 6th International Symposium; Versailles; France, May 2002.

16) Hunt, James L., Laruelle, Gerard, Wagner, Alain, "Systems Challenges for Hypersonic Vehicles;" AGARD Interpanel Symposium on Future Aerospace Technology in Service to the Alliance, NASA-TM-112908, AGARDPaper-C37, 1997.

17) Starr, Brett R.; Westhelle, Carlos H.; Masciarelli, James P., “Aerocapture Performance Analysis For A NeptuneTriton Exploration Mission,” NASA/TM-2006-214300, April 2006. 
18) Bussard, R., "ASPEN II: Two Staging and Radiation Shielding Effects on ASPEN Vehicle Performance," LA26-80, 09/06/1967 and in "ASPEN: Nuclear Propulsion for Earth to Orbit Aerospace Plane Vehicles," Robert W. Bussard, Proceedings International Conference on Spaceflight, Rome. June 1971.

19) Bussard, R., and Jameson, L.W.; "The QED Engine Spectrum: Fusion-Electric Propulsion for Airbreathing to Interstellar Flight," AIAA paper 93-2006, 29th Joint Propulsion Conference, Monterey, CA 6/28 to 6/30/1993; in JPP, Volume 11, Number 2, pp 365/372.

20) Borowski, Stanley K.; Dudzinski, Leonard A.; and McGuire, Melissa L.: "Artificial Gravity Vehicle Design Option for NASA’s Human Mars Mission Using “Bimodal” NTR Propulsion,” AIAA Paper 99-2545, 1999.

21) Kendall, J. S.; Stoeffler, R. C., "Conceptual design studies and experiments related to cavity exhaust systems for nuclear light bulb configurations," Report Number: L-910900-15; NASA-CR-129298

22) Latham, T. S.; Rodgers, R. J., "Small nuclear light bulb engines with cold beryllium reflectors," Report Number: AIAA PAPER 72-1093.

23) Latham, T. S., "Summary of the performance characteristics of the nuclear light bulb engine," Report Number: AIAA PAPER 71-642.

24) Rodgers, R. J.; Latham, T. S., "Analytical design and performance studies of the nuclear light bulb engine," Report Number: L-910900-16; NASA-CR-129295.

25) RONALD GREELEY, et al., "A Scientific Rationale for Mobility in Planetary Environments," Committee on Planetary and Lunar Exploration, National Research Council, NATIONAL ACADEMY PRESS, Washington, D.C. 1999.

26) Herbert, F. and Sandel, B.R., "Ultraviolet observations of Uranus and Neptune," Planetary and Space Science Vol. 47, pp. 1119 to 1139, Published by Elsevier Science Ltd.

27) Sromovsky, L.A., et al., "Episodic bright and dark spots on Uranus” Icarus, Vol. 220 (2012), pp. 6-22.

28) K.A. Rages, H.B. Hammel, A.J. Friedsond, “Evidence for temporal change at Uranus' south pole,” Icarus, Vol. 172 (2004), pp. 548-554).

29) L. A. Sromovsky and P. M. Fry, et al. "Coordinated 1996 HST and IRTF Imaging of Neptune and Triton III: Neptune’s Atmospheric Circulation and Cloud Structure,” Icarus, Vol. 149 (2001)., pp. 459-488.

30) Turba, R.D., "DESIGN OF A NUCLEAR PROPULSION SYSTEM FOR AN UNMANNED AERIAL VEHICLE," Vandebilt University, Masters Thesis, May 2011.

31) Maise, George; Powell, James; Paniagua, John; Ludewig, Hans; Todosow, Michael, "Exploration of Jovian atmosphere using nuclear ramjet flyer," IAF Paper 98-S608, 1998.

32) Borowski, S., "Human lunar mission capabilities using SSTO, ISRU and LOX-augmented NTR technologies A preliminary assessment," AIAA 1995-0026, 1995

33) Robert H. Frisbee* and Ioannis G. Mikellides, "The Nuclear-Electric Pulsed Inductive Thruster (NuPIT): Mission Analysis for Prometheus,” AIAA 2005-3892, July 2005.

34) Grundy, W.M., et al., "Distributions of $\mathrm{H} 2 \mathrm{O}$ and $\mathrm{CO} 2$ ices on Ariel, Umbriel, Titania, and Oberon from IRTF /SpeX observations," Icarus, 184, (2006), 543-555.

35) Brown, M., et al., "Detection of water ice on Nereid," The Astrophysical Journal; 508, L175 to L176, December $1,1998$. 
36) Kevin McPherson, Eric Kelly, Jennifer Keller, ACCELERATION ENVIRONMENT OF THE

INTERNATIONAL SPACE STATION, AIAA-2009-0957, 2009.

37) J. GREEN, W. PILAND, "Impact of artificial gravity on habitability for space base,"

AIAA 7th Annual Meeting and Technical Display, AIAA 1970-1329, 1970.

38) R. A. WENGLARZ, "Problems in altitude control of artificial 'G' space stations with mass unbalance," Journal of Spacecraft and Rockets, 1970, Vol.7: pp. 1161-1166.

39) Jones, R. (editor), "SP-100 planetary mission-system preliminary design study Final report, technical information report," Jet Propulsion Laboratory, JPL D-2513, 1986.

40) Palaszewski, B., "Solar System Exploration Augmented by In-Situ Resource Utilization: Human Planetary Base Issues for Mercury and Saturn,” AIAA 2017-0421, 2017. 